\title{
A Comparison of Supramammillary and Medial Septal Influences on Hippocampal Field Potentials and Single-Unit Activity
}

\author{
SHERI J. Y. MIZUMORI, BRUCE L. MCNAUGHTON, \\ AND CAROL A. BARNES \\ Department of Psychology, University of Colorado, Boulder, Colorado 80309
}

\section{SUMMARY AND CONCLUSIONS}

1. A comparison was made between the influences of supramammillary (SUM) and medial septal (MS) nuclei on hippocampal physiology in Nembutal-anesthetized rats. Specifically, the effects of prestimulation of the SUM or MS on the perforant path-dentate field potential, on spontaneous activity of single units, and on perforant path-induced unit activation were assessed. Another series of experiments addressed the issue of whether the SUM and MS effects on the perforant path-dentate field response are independent.

2. Prestimulation of the SUM or MS significantly facilitated the perforant path-dentate population spike with no clear effect on the field excitatory postsynaptic potential (EPSP) recorded in the subgranular zone of the dentate hilus. Prestimulation of either nucleus also reduced the threshold for spike onset. The major differences between the two spike facilitation effects were the magnitude of the change and possibly the optimal interstimulus intervals required to obtain the effects.

3. Acute transection of the ipsilateral column of fornix or dorsal fornix eliminated the SUM population spike facilitation effect. MS lesion or dorsal fornix/fimbria transection eliminated the MS spike facilitation effect. The MS lesion did not alter the effects of SUM prestimulation. Cingulum or medial forebrain bundle transection affected neither SUM- nor MS-mediated spike facilitation. Thus the SUM and MS influences on the dentate field response appear to be independent of one another. The relevant SUM afferents travel through the ipsilateral column of fornix and dorsal fornix, whereas MS afferents project through the dorsal fornix/fimbria.

4. Single units recorded in stratum granulosum (SG) were assessed with respect to several parameters. These included the mean firing rate, whether or not excitation occurred prior to the field population spike and at lower threshold, and whether or not a driven unit responded to a second perforant path stimulus delivered at short latency following the first (during the period of population spike depression). The latter parameter in particular appeared to separate SG cells into two classes. The cells that were not activated during the second field potential were classified as granule cells, whereas those that were activated were classified as basket cells. Based on this distinction, significant differences were also found between the two cell classes on the other parameters. In particular, cells classified as granule cells often had very low firing rates. We conclude that many previous studies have mistakenly identified as granule cells inhibitory interneurons, which are much more commonly encountered (at least partly due to their higher discharge rates). This misidentification has led to several hypotheses concerning the mechanism of heterosynaptically induced population spike facilitation that we now conclude are untenable.
5. Stimulation of the SUM or MS alone resulted in a reduction in the spontaneous firing rate of more than one-half of the cells recorded in the SG. Based on one or more of the above criteria, these cells were classified as basket cells. Also, stimulation of the SUM or MS prior to perforant path stimulation significantly reduced the probability of basket cell activation by the perforant path stimulus. Roughly $15 \%$ of SG cells recorded showed increased firing in response to SUM or MS stimulation. These cells had very low spontaneous rates and were therefore classified as granule cells. Relatively little change was observed in the firing rates of CA1, CA3, or hilar complex-spike cells. Roughly equal proportions of $\mathrm{CA} 1$ theta cells responded with reduced or elevated firing.

6. Thus, although additional mechanisms may also contribute, the heterosynaptic facilitation of the granule cell population spike is probably largely due to the suppression of inhibitory interneurons, as originally suggested by Bilkey and Goddard $(5,6)$ for the MS-induced effect, on the basis of field potential studies.

\section{INTRODUCTION}

The flow of information through the hippocampus can be influenced by a number of afferent systems that arise from subcortical regions of the brain, such as the medial septum (e.g., Ref. 1), locus coeruleus (e.g., Ref. 8), median and dorsal raphé (e.g., Ref. 4), substantia nigra (32), the parafascicular region (9), and the brain stem reticular formation (38). Another major source of afferents originates in the supramammillary nucleus (SUM) of the hypothalamus (e.g., Refs. 12, 31, 40). Whereas more is becoming known regarding SUM-hippocampal connections, much remains to be discovered regarding the physiological interactions of these two systems. Results to date are somewhat paradoxical. In one study SUM stimulation was found to decrease spontaneous activity of presumed dentate granule cells and CA 1 cells (30), whereas in another study prestimulation of the SUM facilitated the perforant path-dentate population spike (39). The present study was initiated to clarify further the influence of the SUM on hippocampal physiology. In addition, because the reported effects of SUM stimulation were superficially similar to that of the medial septum (e.g., Ref. 1), the influences of septal afferents were assessed for the same cells monitored in the SUM experiments.

Since 1974 (31) it had been known that a direct projection exists between the SUM and hippocampus of rats. Amaral and Cowan (2) later showed that HRP injected into monkey hippocampus also results in labeled cells in the 

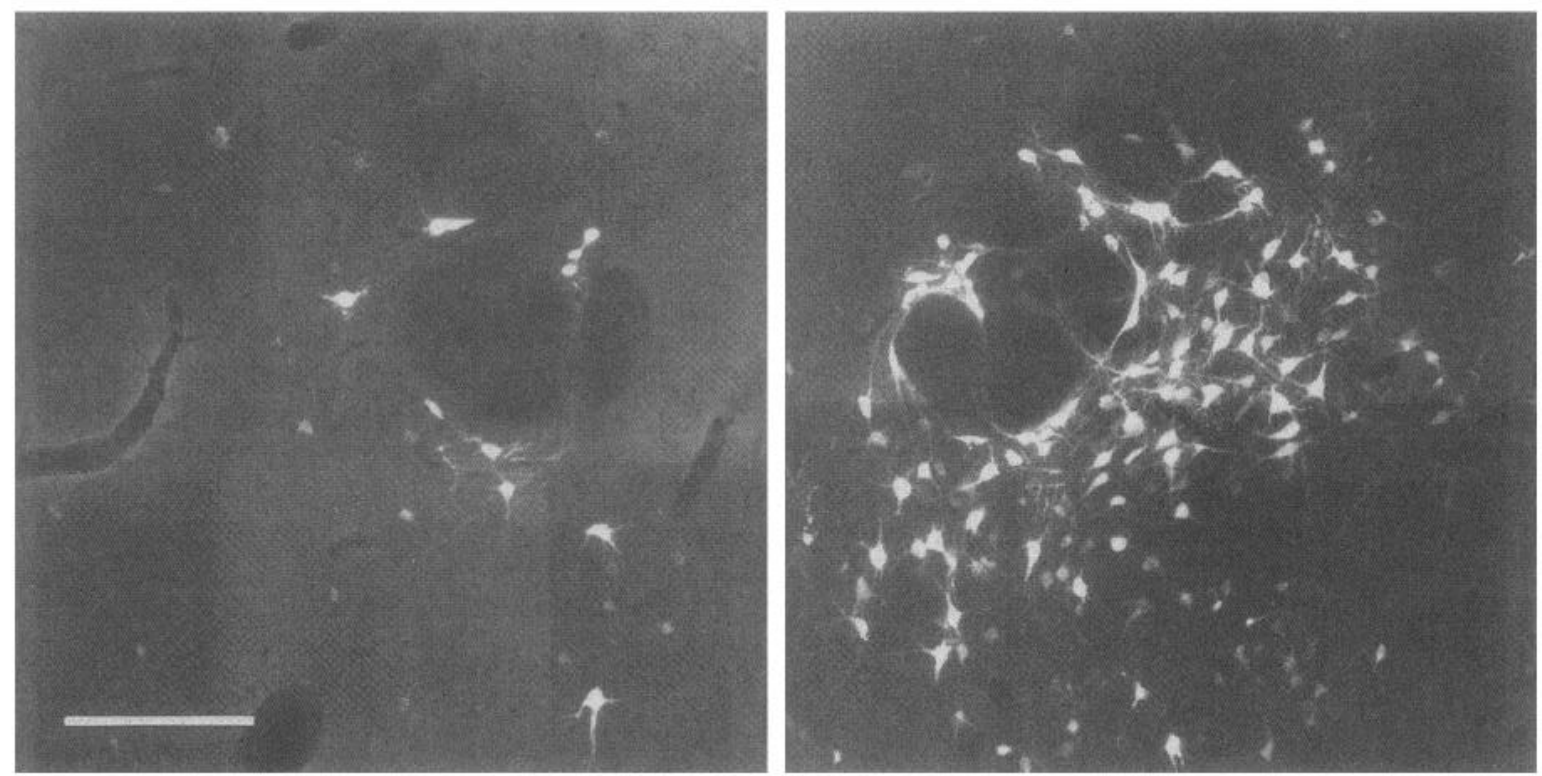

FIG. 1. Horizontal sections (AP-4.5 mm from bregma and $-8.4 \mathrm{~mm}$ from top of brain) illustrating retrogradely labeled SUM cells 7 days following a unilateral injection of fluoro-gold into rat hippocampus (28). The ipsilateral supramammillary nucleus (SUM) is shown on the right, with the midline situated between the 2 photographs. As described by others (see text), these photographs illustrate that the SUM-hippocampal projection is primarily ipsilateral, although some contralateral SUM cells were also labeled. The close relationship between the location of SUM cells and the mammillothalamic tract is evident (calibration $250 \mu \mathrm{m}$ ).

SUM. Furthermore, it was noted that more cells ipsilateral to the site of injection were labeled than cells in the contralateral SUM. Experiments involving injection of labeled amino acid into the SUM of rats $(31,40)$, cats $(40)$, and monkeys (34) revealed the highest area of labeling to be in the granule cell layer of the dentate gyrus, and the immediately adjacent areas of the molecular layer. Labeling occurred along the entire septotemporal extent of the dentate, with ipsilateral labeling being considerably more extensive than contralateral labeling.

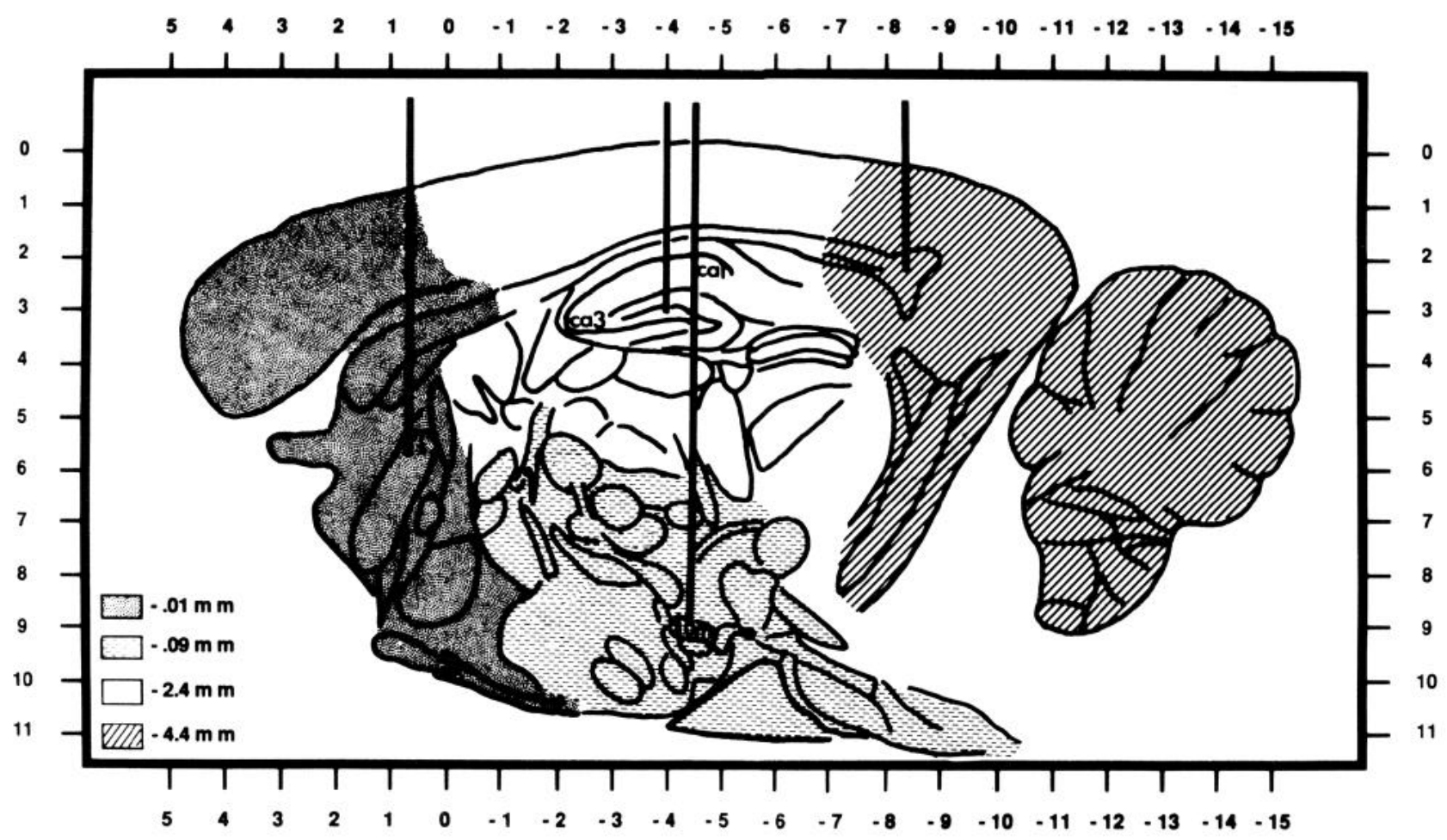

FIG. 2. Schematic diagram of a saggital view of the rat brain illustrating electrode placements. Different lateral coordinates are as indicated in the bottom left corner. The electrodes were situated in (from left to right) the medial septum (MS), the fascia dentata, the supramammillary nucleus (SUM), and the perforant path. (Adapted from Ref. 21) 
The conclusion that a large number of SUM efferents terminate in the dentate gyrus was further supported by the finding that local application of the retrograde tracer Evans blue to the upper blade of the dentate produced labeled cell bodies in the SUM region (13). Labeling was observed throughout an extensive rostrocaudal aspect of the SUM. A recent experiment conducted in our laboratory confirmed this distribution of SUM cells following injection of a different retrograde tracer, fluoro-gold, into the dentate gyrus (see Fig. 1). Amaral and Cowan (2) and Harley et al. (13) postulated that hippocampal afferents from the SUM involve at least as many efferent cells as those from the septum.

A recent reexamination of SUM afferent and efferent systems combined retrograde labeling with true blue or fast blue, and anterograde labeling with phaseolus vulgaris leucoagglutinin (PHA-L) techniques (12). This report described a more widespread distribution of SUM efferents to the hippocampus than had been shown in previous tract tracing studies. Following injection of PHA-L into the lateral SUM, varied amounts of label were found in all regions of the hippocampus on the ipsilateral side, as well as in the dentate region and Ammon's horn of the contralateral side. In contrast to results of previous studies, Haglund et al. found moderate amounts of label in CA3a of Ammon's horn, in particular the pyramidal layer and stratum oriens. Only very sparse labeling was found in CA2 and CA1.

The specific pathway containing SUM efferents to the hippocampus remains debatable. The medial forebrain bundle (e.g., Refs. 12, 40) and fornix (e.g., Ref. 34) have been suggested as likely candidates. More specifically, Veazey et al. postulated that the medial forebrain bundle carries SUM efferents to septal nuclei, whereas the fornix carries efferents to the hippocampus. At the level of dorsal hippocampus, labeled fibers have been described in the fimbria (12) or the subcallosal fornix (40).

Detailed descriptions of the anatomic connections between the medial septum (MS) and the hippocampus can be found elsewhere (e.g., Refs. 20, 33). Briefly MS afferents arrive in hippocampus via the fimbria, fornix, and the cingulum. Septal terminals have been identified in most regions of the hippocampus, although the most dense projection is to the subgranular hilar region of the dentate gyrus.

Four experiments were conducted to assess the physiological significance of the SUM afferent system. First, the effects of SUM stimulation on the perforant path-dentate (PP-FD) field response were examined. The second experiment assessed the effects of SUM stimulation on the spontaneous firing rate of different populations of hippocampal units. To determine whether units recorded within the stratum granulosum (SG) in experiment 2 were granule or basket cells, experiment 3 examined the influence of SUM stimulation on perforant path-induced activation of individual SG units. Information regarding the relative influence of the SUM afferent system was obtained by comparing the physiological responses of the same cells to both SUM and MS stimulation in experiments 1, 2, and 3. Finally, additional rats sustained lesions of either the MS, ipsilateral column of fornix, medial forebrain bundle, cingulum, dorsal fornix, or fimbria to determine whether the SUM and MS effects on the PP-FD field potential were independent of one another. Some of the results included in this paper have been presented in abstract form (19).

\section{METHODS}

Nine-month old male Fischer-344 rats (retired breeders) were obtained from Charles River Laboratories (Kingston, N.Y.). A total of 61 rats were used. On arrival the rats were singly housed and given free access to food and water. The rats were allowed to adapt to the colony room for 2-4 wk before taking part in the experiments. Experiments were conducted between 0700 and $1900 \mathrm{~h}$. Lights were on in the colony room between 0600 and $1800 \mathrm{~h}$.

\section{Surgical procedures}

The rats were deprived of food and water for $24 \mathrm{~h}$ before surgery. The initial dose of pentobarbital sodium (Nembutal, 50 $\mathrm{mg} / \mathrm{ml}$ ) was $30 \mathrm{mg} / \mathrm{kg}$ body weight. Supplements of $0.05 \mathrm{ml}$ ip
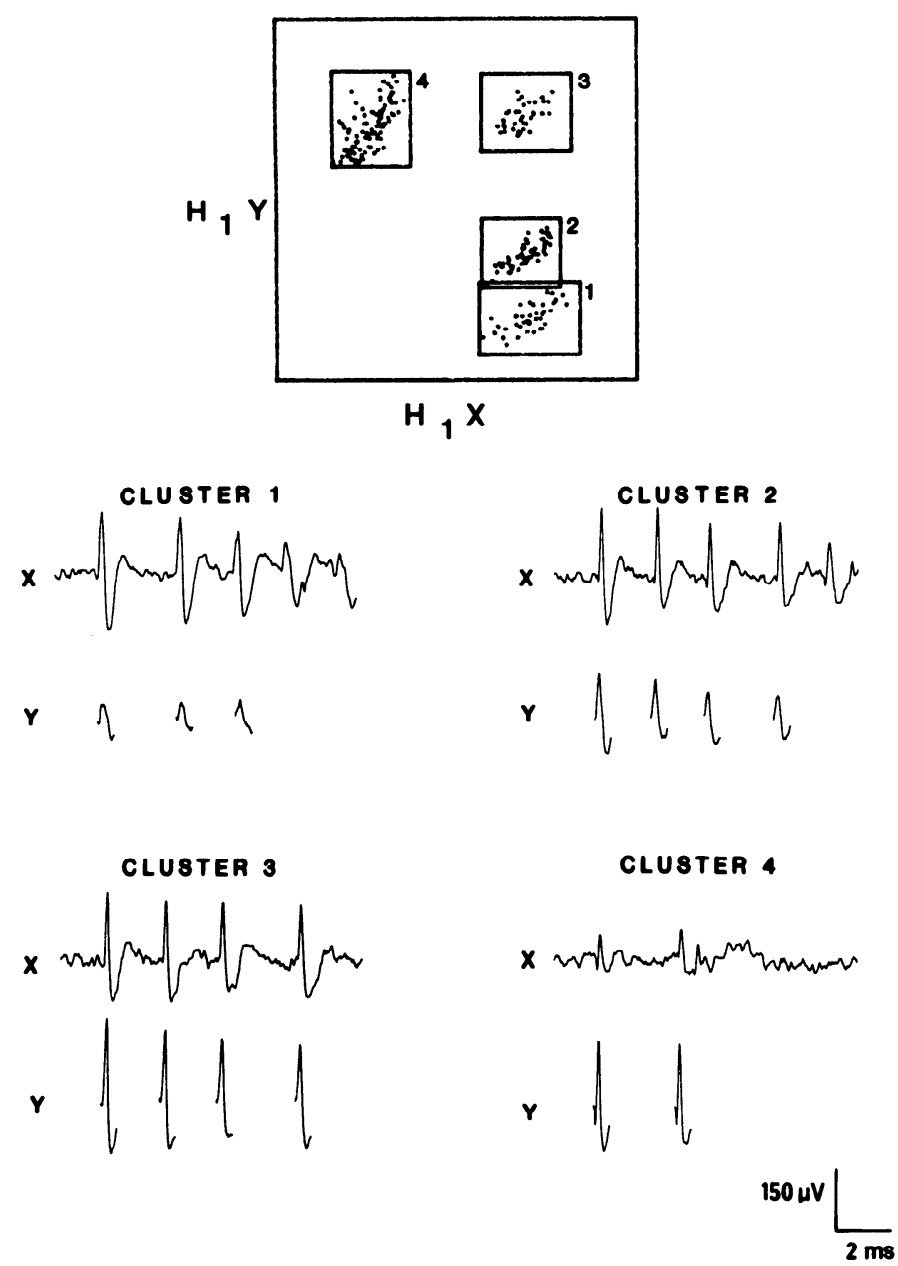

FIG. 3. An example of 4 , simultaneously recorded hilar complex-spike cells separated according to the ratio of the height of the first peak on the $\mathrm{X}$-channel $\left(\mathrm{H}_{1} \mathrm{X}\right)$ and the height of the first peak on the $\mathrm{Y}$-channel $\left(\mathrm{H}_{1} \mathrm{Y}\right)$. Each dot on the scatter plot represents the occurrence of 1 spike. Successive spikes within a burst appear on the scatter plot as a series of dots directed toward the origin. Boxes enclose clusters of dots that represent single units. The corresponding analog waveforms of these cells are shown below the scatter plot. The top trace $(\mathrm{X})$ represents the signal on the $X$-channel. The lower trace (Y) illustrates the signal on the Y-channel. A DC offset was introduced into the Y-channel except during the 1-ms sampling period. This enabled observation of the precise analog signal being sampled. 
were injected as necessary for the evoked potential experiments. Continuous intraperitoneal infusion of $25 \mathrm{mg} / \mathrm{ml} \mathrm{Nembutal}$ $(0.075 \mathrm{ml} / \mathrm{h})$ was employed for the remaining experiments.

Each rat was maintained in a stereotaxic apparatus for the duration of the recording session. An incision was made along the midline of the scalp to expose the skull. Small burr holes were drilled in the skull at the appropriate stereotaxic coordinates. The dura was carefully slit to permit unobstructed insertion of the electrodes into the brain. Stimulating and recording electrodes were situated in the brain as illustrated in Fig. 2, according to the following coordinates (horizontal skull; Ref. 21): medial septum (MS): AP0.7 $\mathrm{mm}$ anterior to bregma, L0.0 $\mathrm{mm}$ (midline), DV $-5.7 \mathrm{~mm}$ from brain surface; supramammillary nucleus (SUM): AP $-4.5 \mathrm{~mm}, \mathrm{~L}-0.5$ to $-1.0 \mathrm{~mm}, \mathrm{DV}-8.0$ to $-8.4 \mathrm{~mm}$; perforant path (PP): AP-8.1 mm, L-4.4 mm, DV-3.3 mm. Recording electrodes were positioned $4.0 \mathrm{~mm}$ postcrior to bregma and $2.4 \mathrm{~mm}$ left of the midsaggital suture. The DV coordinate of the recording electrode was determined using electrophysiological criteria.

At the end of the experiment each rat was perfused intracardially with $0.9 \% \mathrm{NaCl}$, then $10 \%$ formalin. The brains were removed, then allowed to sink in $30 \%$ sucrose formalin for at least 48 h. $40-\mu \mathrm{m}$ thick frozen sections were stained with cresyl violet for identification of electrode placements.

\section{SUPRAMAMMILLARY}
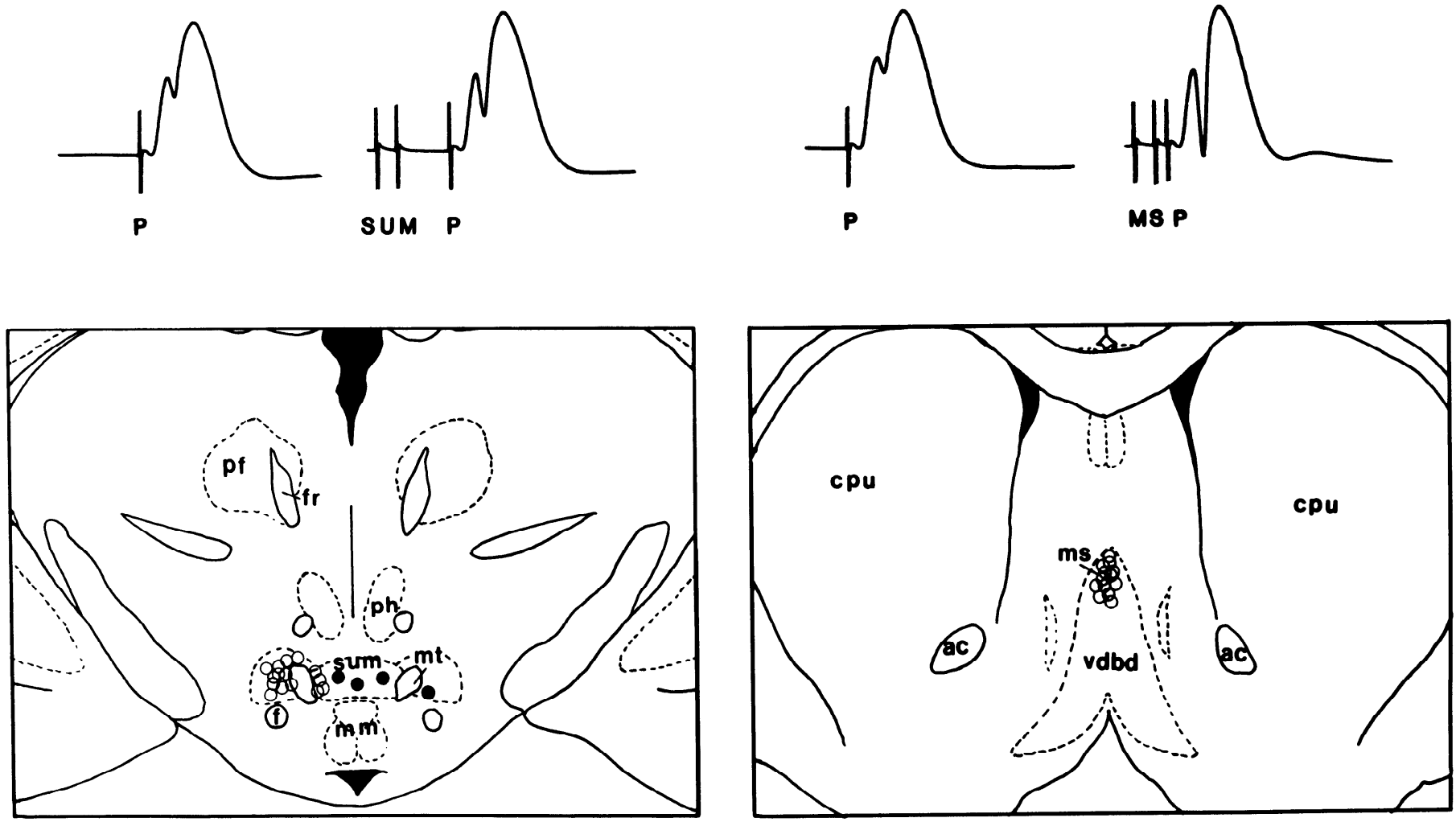

\section{Field potentials}

The stimulating electrodes (150-200 k $\Omega$ ) were manufactured from $114 \mu \mathrm{m}$ od Teflon-coated stainless steel wire. Two hundred $\mu \mathrm{m}$ of insulation was stripped from the tip of the perforant path stimulating electrode. MS and SUM stimulating electrodes were insulated up to the tip and cut blunt. Stimulus return leads were soldered to jewelers screws, then anchored to the skull. All stimuli were diphasic. Test pulses $(1-20 \mathrm{~V} ; 100-\mu \mathrm{s}$ pulse width for each half cycle) were delivered to the perforant path at a rate of $0.1 \mathrm{~Hz}$. The perforant path stimulus intensity selected for those parametric experiments that varied the interstimulus interval and/or the intensity of MS and SUM stimulation reflected the voltage required to elicit a population spike that was $\sim 30 \%$ of the maximum spike amplitude. MS and SUM cells were stimulated by applying 2 pulses (2.5 ms apart; $100-\mu$ s duration) to the MS or SUM region. Activation of the Frederick-Haer Pulsar 6-bp stimulators was controlled by a PDP-11/23 computer during the recording session. The particular voltage applied to the MS or SUM depended on the specific purpose of each experiment. The interval between MS or SUM stimulation and the perforant path pulse ranged from 3 to $3,000 \mathrm{~ms}$. The particular sequence of voltage or interstimulus interval tested was randomly determined. Stimulation of perforant path alone, SUM and perforant path, or MS and perforant path was delivered in an alternating sequence.

\section{MEDIAL SEPTUM}

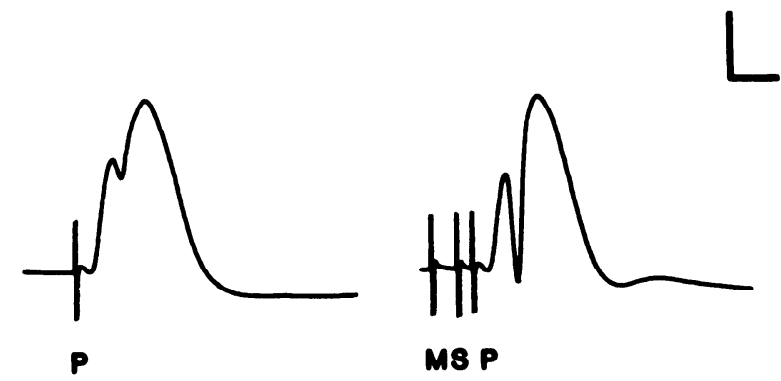

FIG. 4. Examples of PP-FD spike facilitation by prestimulation of the supramammillary nucleus (SUM) (top left) or MS (top right). The field potential shown represents the mean response following 10 SUM-PP or MS-PP stimulus pairings (calibration: $5 \mathrm{~ms}, 10 \mathrm{mV}$ ). Bottom left: electrode placements indicating the range of effective $(0)$ and noneffective $(\bullet)$ SUM stimulation sites. The SUM ipsilateral to the recording electrode is shown on the left. Stimulation sites in the medial SUM were less effective than those in lateral SUM. Contralateral prestimulation produced no significant change in the PP-FD field response. Bottom right: an illustration of the range of stimulating electrode placements within the MS. Significant MS-induced spike facilitation was obtained in all cases. (Adapted from Ref. 21) 
Except where indicated, hippocampal field potentials were recorded through insulated, sharpened nichrome wire $(60-\mu \mathrm{m}$ diameter; 400-500 k $\Omega$ ). Reference and ground leads were soldered to jewelers screws that were attached to the skull. The analog signal was amplified 100-200 times, depending on the magnitude of the potential, then band-pass filtered between $0.5 \mathrm{~Hz}$ and 5 $\mathrm{kHz}$. The signal was displayed on a Nicolet 3091 oscilloscope for on-line monitoring of the potential during and between recording sessions. Evoked potentials were sampled by the PDP-11/23 computer at $10 \mathrm{kHz}$ and stored for subsequent analysis. Different measures were used to assess prestimulation-induced alterations of the PP-FD field potential. The EPSP measurement reflected the amplitude, at a fixed latency, of the (initial) rising phase of the field response. Changes in the population spike were monitored in terms of the area under a tangent line drawn between the two positive peaks of the potential, the latency to the negative peak of the potential, spike height, spike width, and the height of the EPSP at spike onset.

\section{Single-unit recording}

The "stereotrode" recording technique (17) used in the present study involved independently recording signals through two insulated, 20- $\mu \mathrm{m}$ tungsten wires (California Fine Wire, Co.) bonded together with Epoxylite. The pair of wires was mechanically sharpened, and the tip was electroplated with gold, giving a final impedance at $1 \mathrm{kHz}$ of $200-400 \mathrm{k} \Omega$. The center-to-center spacing of the wires was $\sim 35 \mu \mathrm{m}$. Reference and ground leads were connected to anchor screws on the skull. Briefly the stereotrode recording technique is based on the principle that the amplitudes of the analog signals of cells near the electrode tips vary as a function of the relative distance of individual cells from each electrode tip. Therefore, if cell $A$ is closer to electrode $\mathrm{X}$ than to electrode $\mathrm{Y}$, the amplitude of cell $A$ 's action potentials will appear larger on the $\mathrm{X}$-channel than on the Y-channel. Scatter plots of spike amplitude on the $\mathrm{X}$ - and $\mathrm{Y}$-channels reveal distinct clusters, presumably corresponding to single units located at different relative distances from the $\mathrm{X}$ - and $\mathrm{Y}$-electrode tips (see Fig. 3).

The incoming signal from each recording electrode was amplified independently (times 5-10 K), then band-pass filtered between 600 and $800 \mathrm{~Hz}$ and $5 \mathrm{kHz}$. The analog signal for each electrode was then passed through a window discriminator such that if the amplitude of either of the signals was greater than a predetermined threshold, a 1-ms sampling interval began. During this period, four spike parameters for each channel (the maximum and minimum voltages of the analog signal and the latency of these values from the onset of the sampling period) were calculated in hardware by a spike processor (FMZ Electronics Co.). These eight spike parameters were collected by a PDP-11/23 computer that also logged the time of the event. After the recording session the eight spike parameters were used to separate the event sequences of individual cells using a multidimensional cluster analysis program (McNaughton, unpublished). Thus the multiunit record was decomposed into its component single units.

The effects of stimulation of the MS or SUM on the spontaneous firing rate of different hippocampal cell types were monitored. Depressing particular keys on the keyboard activated the stimulators and logged the time of key depression. On receiving a signal from the computer, the stimulators delivered 2 pulses ( 15 $\mathrm{V}, 100-\mu \mathrm{s}$ duration, $2.5 \mathrm{~ms}$ apart) to either the MS or SUM. Successive stimulations occurred 10-15 s apart. A given cell's response to each type of stimulation was tested at least 40 times. The order of nuclei stimulated was randomly determined. Selection of the particular stimulation parameters used for this experiment was based on the results of the SUM- and MS-induced PP-FD spike facilitation experiments described above.
To assess whether SUM or MS stimulation alters perforant path-induced activation of SG units, base-line activity of single units was first recorded to obtain measures of the mean spontaneous firing rate, rhythmicity of spontaneous discharge, and spike duration. Leaving the stereotrode in place, the filter and gain settings were then adjusted to allow recording of the PP-FD field potential through one channel $(0.5 \mathrm{~Hz}-5 \mathrm{kHz}$; gain of 100) while monitoring unit activation through the other channel $(600 \mathrm{~Hz}-6$ $\mathrm{kHz}$; gain of 2,000). A series of tests was conducted to facilitate classification of the unit. I) Two pulses were delivered to the
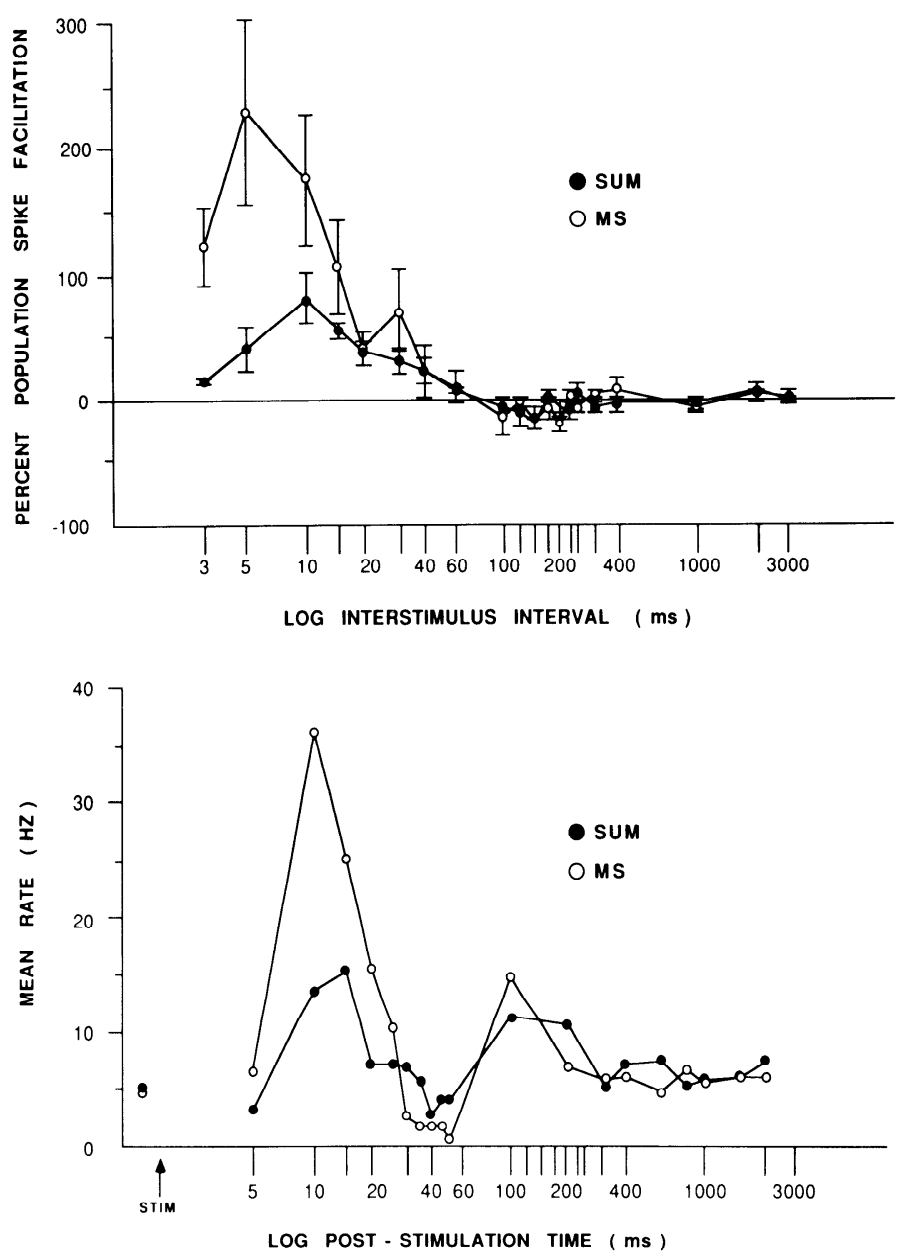

FIG. 5. Top: mean ( \pm SE) SUM- and MS-induced spike facilitation as a function of the interval between the prestimulation pulses and perforant path stimulus. The stimulus intensities were held constant (SUM or MS: $15 \mathrm{~V}$, perforant path: $10 \mathrm{~V}$ ). Each of the 5 rats tested contributed data to all time points indicated on the absissa. For each rat, 10 sets of test pulses were delivered and the average spike facilitation calculated. The data points presented above represent the average facilitation across rats. MSinduced spike facilitation was maximal when the interstimulus interval was $5 \mathrm{~ms}$, although facilitation was also observed with intervals as long as $30 \mathrm{~ms}$. SUM-induced spike facilitation was optimal at interspike intervals of $10-15 \mathrm{~ms}$. Prestimulation of either the MS or SUM resulted in a small, but significant, degree of inhibition of the population spike at intervals of 100-200 ms. No effect of prestimulation was observed when intervals of $>200 \mathrm{~ms}$ were employed. Bottom: the mean firing rate of all cells recorded in stratum granulosum (SG) following SUM or MS stimulation. Although the predominant unit response to stimulation was either no change or a reduction in firing (see Fig. 10), the net population response shortly after stimulation was an elevated rate of firing. Thus the overall early increase in the average across cells was due to a large increase in a small proportion of cells recorded. The initial period of excitation was followed first by a mean reduction in activity, then by a second peak of excitation. The second peak was probably due to the postinhibitory excitation observed for many cells. 
perforant path $(25-\mathrm{ms}$ interstimulus interval) at a rate of $0.1 \mathrm{~Hz}$. Unit activation and the presence of a population spike during both field potentials was monitored for at least 25 such pairedpulse stimulations. 2) Unit activation was also recorded as a function of perforant path intensity. 3) The latency to activation at the maximum stimulus intensity was noted. 4) The effects of SUM or MS prestimulation on the probability of perforant path-induced unit discharge were determined.

\section{Electrolytic lesion}

Five rats sustained an electrolytic lesion of the MS after parametric data on MS- and SUM-spike facilitation were collected. Using the optimal stimulation parameters for obtaining both forms of spike facilitation, prelesion quantification of the facilitation effect was again recorded. To produce an MS lesion that was $\sim 1.0 \mathrm{~mm}$ in diameter, $0.8 \mathrm{~mA}$ current (negative polarity) was passed through the MS stimulating electrode for $8 \mathrm{~s}$. Pre- and postlesion test pulses to the perforant path alone, or perforant path preceded by MS or SUM stimulation, occurred at a rate of $0.1 \mathrm{~Hz}$

Fornix, medial forebrain bundle, cingulum, and fimbria transection

Transections were carried out with a small piece of a razor blade ( $1 \mathrm{~mm}$ wide and $8 \mathrm{~mm}$ long). The razor blade was glued to an insect pin, which in turn was mounted in a stereotaxic micromanipulator. Electrodes were placed in the perforant path, dentate hilus, SUM, and MS such that MS- and SUM-induced PP-FD spike facilitation was maximized. In different rats either

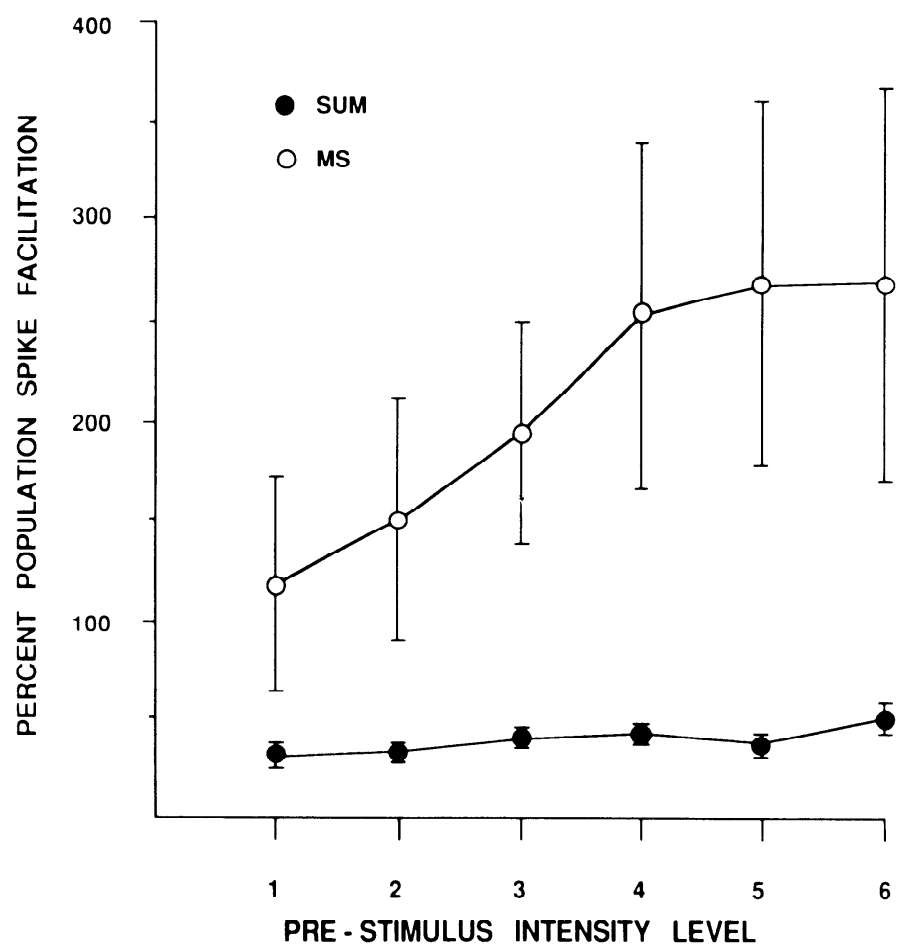

FIG. 6. Mean ( \pm SE) SUM and MS spike facilitation as a function of prestimulation intensity level. Each of 6 rats were tested at all intensity levels. Level 1 represents the stimulus intensity required to obtain the smallest, yet clearly observable, spike facilitation effect. The lowest voltage tested was $6 \mathrm{~V}$. The range of intensities represented by level 1 was $6-10 \mathrm{~V}$ or 10-15 V for MS or SUM stimulation, respectively. Each successive increment in intensity level represents an increase of $2 \mathrm{~V}$. These data indicate that the maximum obtainable spike facilitation is considerably larger for MS prestimulation than for SUM prestimulation.

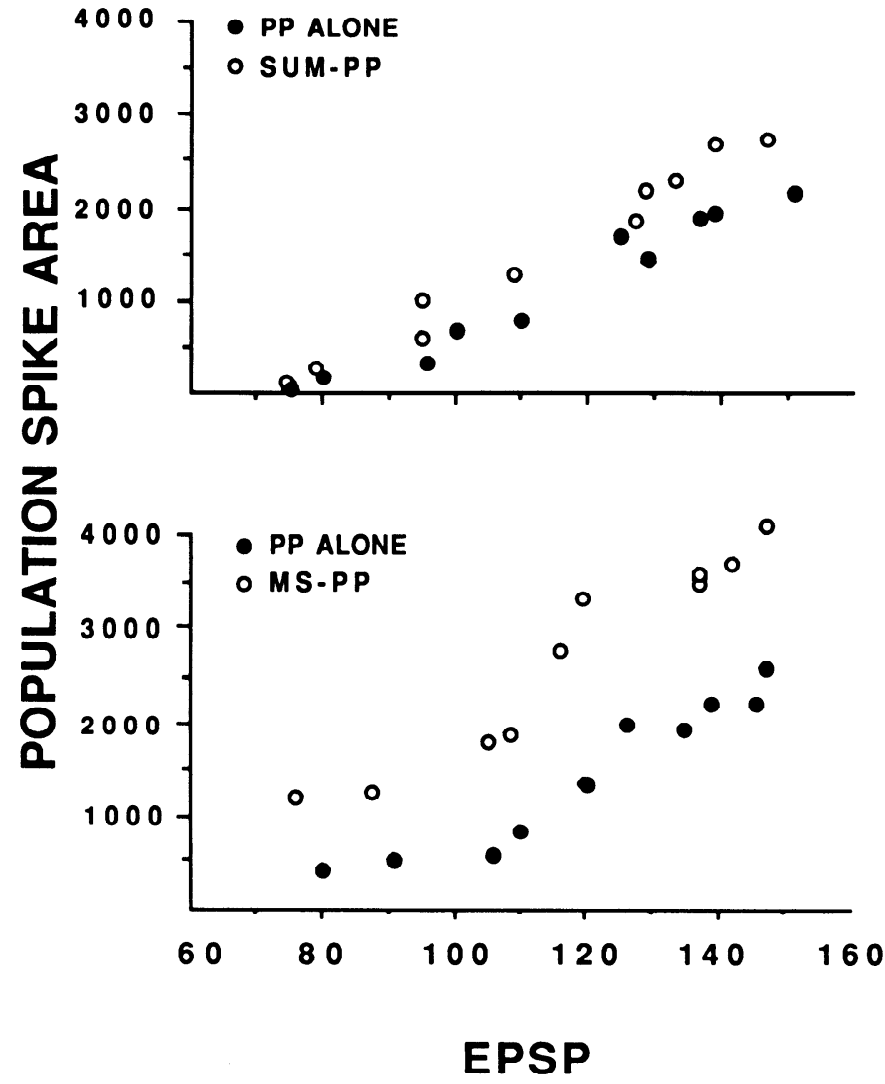

FIG. 7. SUM- and MS-induced spike facilitation as a function of EPSP amplitude $(n=6)$. In general, the relative growth of the population spike is inversely related to the control spike amplitude.

the ipsilateral column of fornix or medial forebrain bundle was transected by lowering a knife that was positioned $1.3 \mathrm{~mm}$ posterior to bregma and $4.5 \mathrm{~mm}$ lateral to the midsaggital suture. The knife was angled 29 or $30^{\circ}$ laterally toward the midline for medial forebrain bundle or fornix cuts, respectively. PP-FD spike facilitation was monitored every $0.5 \mathrm{~mm}$ that the knife was advanced, beginning $2.5 \mathrm{~mm}$ below the brain surface. Additional rats each received knife cuts of the ipsilateral cingulum, dorsal fornix, and fimbria by first lowering a knife (AP-1.3 mm; L1.0 mm) to 1.2 $\mathrm{mm}$ below the brain surface, then advancing in $0.3-\mathrm{mm}$ steps until spike facilitation was no longer observed, or until the knife was advanced $5.0 \mathrm{~mm}$. PP-FD spike facilitation was recorded after each knife advancement (see Fig. 17).

\section{RESULTS \\ Effects of SUM or MS prestimulation on the PP-FD field potential}

An illustration of the range of electrode placements within the SUM and MS can be found in Fig. 4. Prestimulation of the SUM region resulted in a $75 \%$ increase in the area of the PP-FD population spike, with no significant change in spike peak latency, $0.4 \pm 0.4$ (SE) \%, or EPSP amplitude, $1.0 \pm 4.2 \%$ (see Fig. 4, upper left). This result is consistent with that reported by Winson (39). The EPSP amplitude at spike onset was reduced by $4.5 \%( \pm 1.7)$. A similar pattern of effects was obtained if the MS was activated shortly before perforant path stimulation (spike: $264 \pm 3.4 \%$; EPSP: $-3.3 \pm 4.7 \%$; peak latency: $0.6 \pm 0.4 \%$; EPSP amplitude at spike onset: $-12.4 \pm 3.2 \%$ ), a finding 
INTERSPIKE INTERVAL
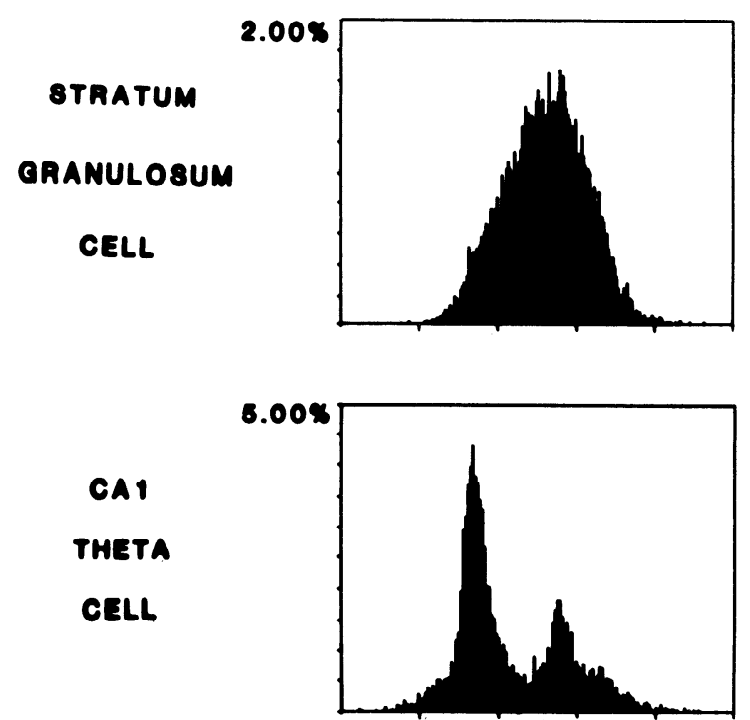

CA1

THETA

CELL

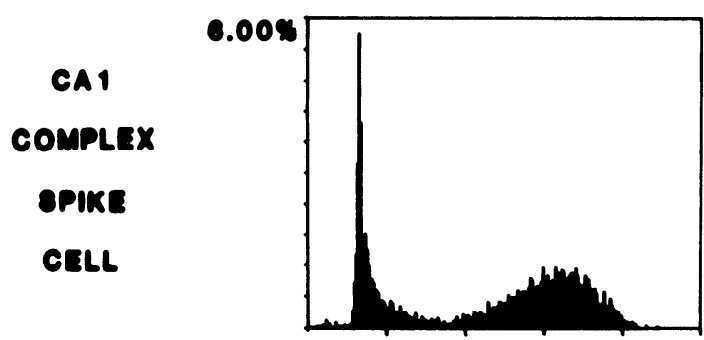

\section{$4.00 \%$}

CAS

COMPLEX

opIKE

CELL

\section{MILAR \\ COMPLEX \\ BPIKE \\ CELL}

AUTOCORRELATION

$0.00 \mathrm{HZ}$

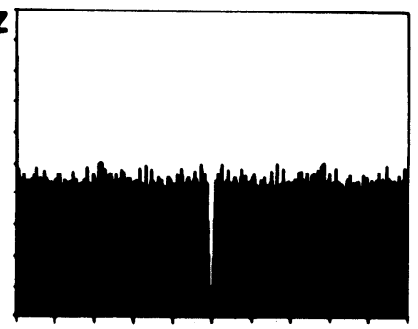

$40.00 \mathrm{HZ}$

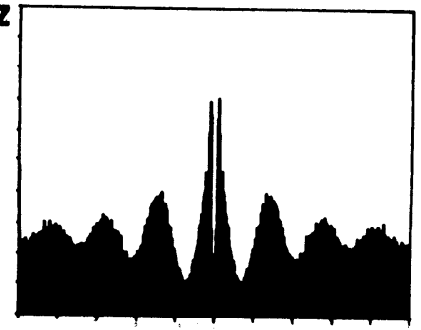

$60.00 \mathrm{~Hz}$

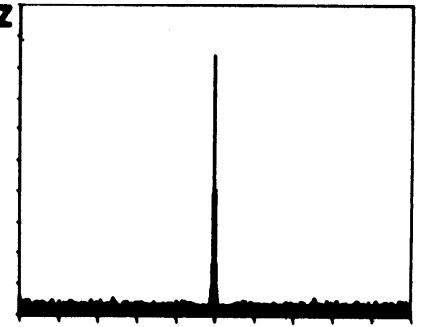

$80.00 \mathrm{~Hz}$
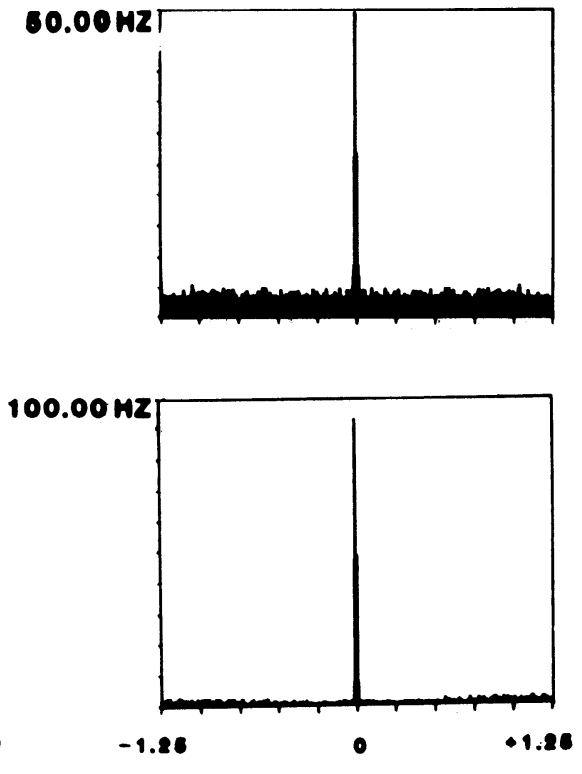

TIME (BEC)

FIG. 8. Examples of interspike interval histograms and autocorrelation functions for representative cells from the different populations recorded. A unimodal distribution of intervals was characteristic of about $80 \%$ of cells recorded in stratum granulosum (SG). In contrast, a bimodal interspike interval distribution was characteristic of a large number of theta cells. The autocorrelation functions of SG cells were relatively flat, whereas those of CA1 theta cells were often rhythmically modulated at a frequency of $\sim 3 \mathrm{~Hz}$. Complex-spike cells recorded from different regions within the hippocampus had similar characteristic within burst interspike intervals of $\sim 2.5-4.0 \mathrm{~ms}$. Successive bursts occurred at a frequency of $\sim 2-3 \mathrm{~Hz}$. 
consistent with those reported by others (e.g., Ref. 1). The most obvious difference between the effects of SUM and MS prestimulation was that, given the same stimulus intensity of $15 \mathrm{~V}$, the former typically resulted in population spike facilitation that was about one-third of the magnitude of the latter. In addition, whereas septal stimulation resulted in a clear (septodentate) evoked potential in $\sim 20 \%$ of the preparations, SUM stimulation did not.

A gradient of effectiveness of SUM stimulation was observed such that the more lateral the electrode placement, the greater the spike facilitation (see Fig. 4, lower left). When a stimulating electrode was placed in medial or contralateral SUM, little or no significant spike facilitation was observed (i.e., $<10 \%$ ). These data are consistent with tract tracing experiments indicating that more cells from the ipsilateral lateral SUM project to the dentate than from the medial or contralateral SUM (e.g., Ref. 12; see also Fig. 1).

SUM- and MS-induced spike facilitation effects were monitored as the interval between the prepulses and the perforant path pulse was varied randomly from 3 to 3,000 $\mathrm{ms}(n=5)$, and prepulse intensity varied from 10 to $20 \mathrm{~V}$. Figure 5 (top) compares the extent of SUM- and MS-induced spike facilitation for the intermediate intensity (15 $\mathrm{V})$ as a function of the interstimulus interval. The interval that produced the largest MS spike facilitation was always 5 $\mathrm{ms}$, while the optimal interval for SUM spike facilitation varied between 10-15 ms. No significant change in EPSP measures was observed even at these optimal intervals (MS: $3.6 \pm 4.1 \%$; SUM: $-1.0 \pm 2.2 \%$ ).

As the interstimulus interval was extended to 150 or 200 $\mathrm{ms}$, MS or SUM stimulation produced a small but significant reduction of the population spike area with no clear

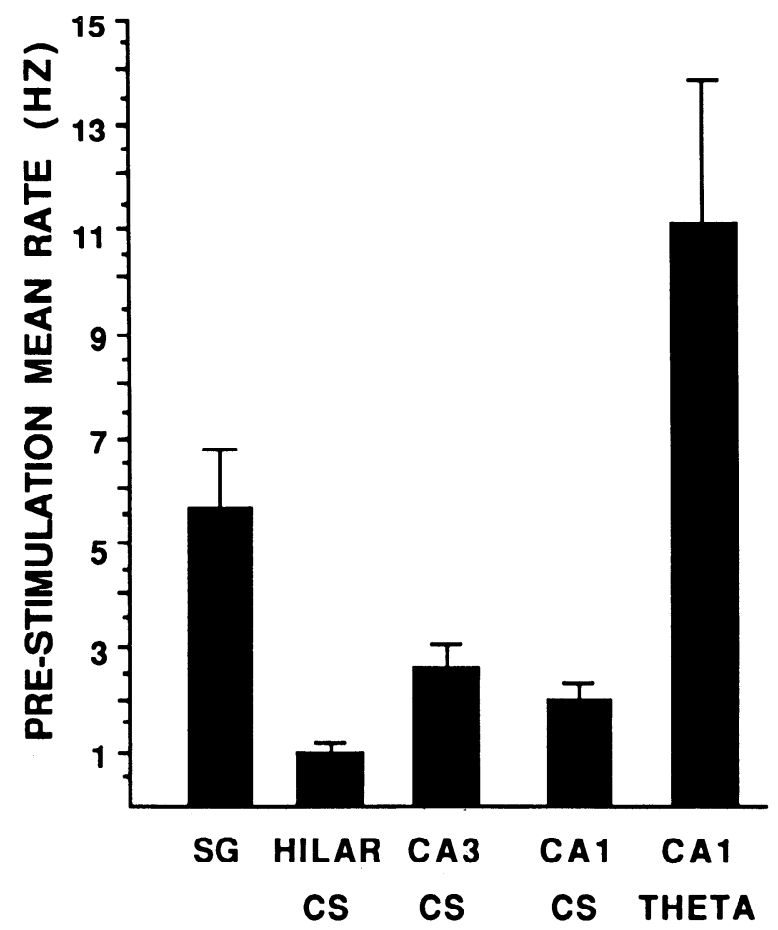

FIG. 9. Mean ( \pm SE) spontaneous firing rate of different cell types $2.5 \mathrm{~s}$ before a stimulation event. CA1 theta cells consistently exhibited a higher rate of firing than any other cell type recorded, followed by units recorded in the stratum granulosum (SG) of the dentate gyrus. Hilar complex-spike cells fired at a lower rate than CA 1 or CA3 complex-spike cells.

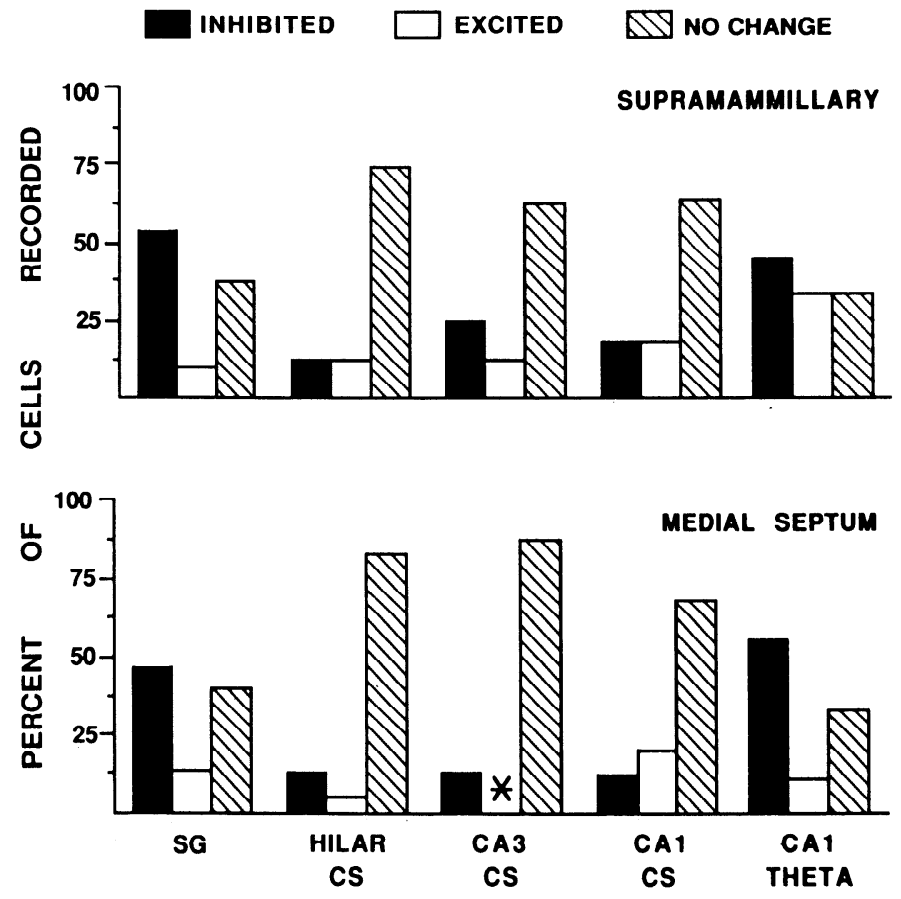

FIG. 10. For each cell type, the percentage of cells recorded that responded by inhibition, excitation, or showed no change in firing rate following SUM or MS stimulation. Either form of stimulation produced similar patterns of effects on the different cell populations. The predominant effect observed for units recorded in the stratum granulosum (SG) was reduced spontaneous firing. Relatively little effect was observed on complex-spike cells following SUM or MS stimulation. Similar proportions of inhibitory and excitatory influences on CA1 theta cells were noted following SUM stimulation. There was an apparent predominance of inhibitory responses following MS stimulation. Asterisks indicate no observations of a particular effect following stimulation.

change in the EPSP. MS or SUM stimulation at higher intensities did not increase the spike reduction effect, but lower intensities reduced it (data not shown). Interstimulus intervals of $>200 \mathrm{~ms}$ resulted in no prestimulation effects on the population spike or EPSP measures.

Figure 6 shows that varying the intensity of the prepulse, while keeping the perforant path intensity $(10 \mathrm{~V})$ and the interstimulus interval constant $(5 \mathrm{~ms}$ for MS; $15 \mathrm{~ms}$ for SUM), produced a different pattern of effect depending on whether the SUM or MS was stimulated $(n=6)$. Increasing the SUM intensity did not produce as great a corresponding increase in the extent of spike facilitation as was observed by increasing the intensity of MS prepulses. At the lowest prestimulation intensity used, the ratio of the magnitude of MS-induced spike facilitation to SUM-induced spike facilitation was $\sim 3: 1$. At the highest intensity, the ratio was $6: 1$.

Varying the intensity of the perforant path pulse while keeping the prestimulation variables constant ( 2 pulses, 15 $\mathrm{V}, 5 \mathrm{~ms}$ interstimulus interval for MS and $15 \mathrm{~ms}$ interstimulus interval for SUM) revealed similar patterns of effect for MS and SUM activation. When the perforant path intensity was below the threshold for eliciting a PP-FD population spike, prestimulation of the SUM or MS often induced a clear population spike. When the perforant path intensity was just above the threshold for obtaining a reliable but small population spike, both SUM and MS presti- 
SUPRAMAMMILLARY
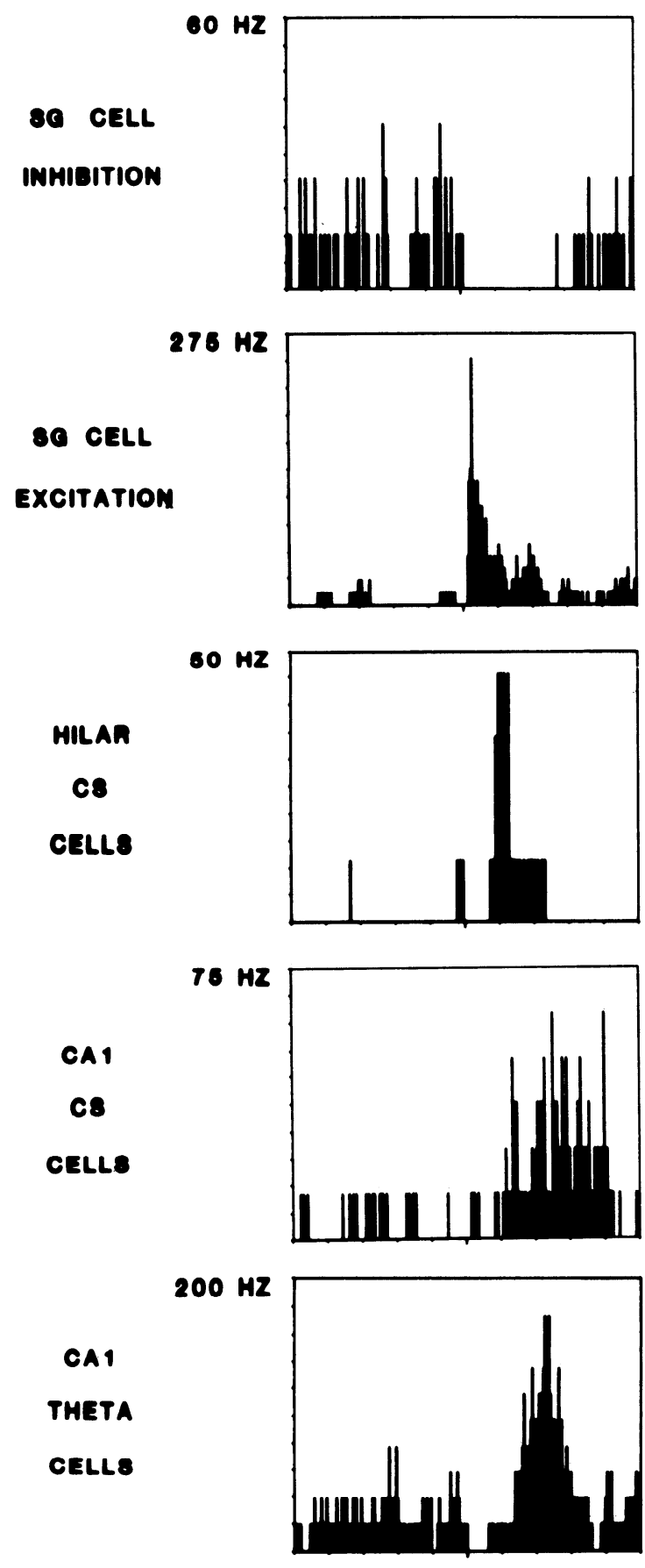

$70 \mathrm{HZ}$

MEDIAL SEPTUM

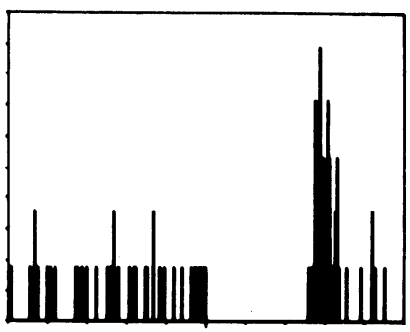

$400 \mathrm{HZ}$

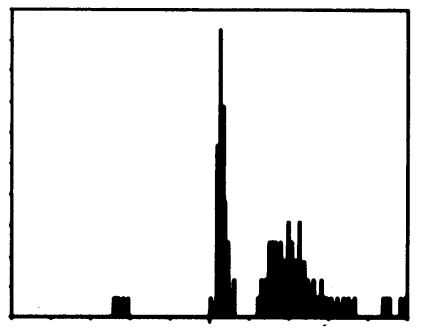

$126 \mathrm{HZ}$

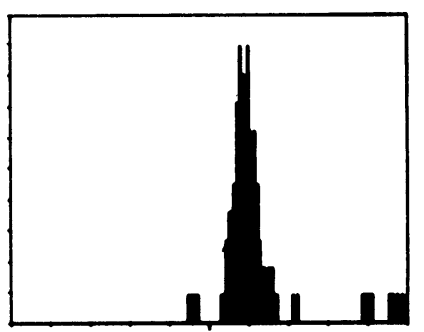

$100 \mathrm{~Hz}$

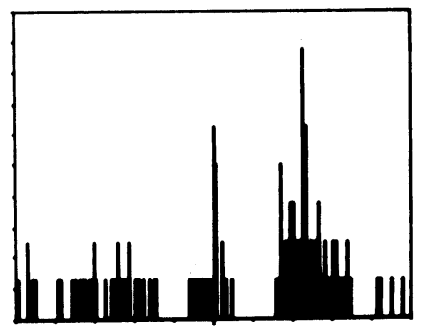

$100 \mathrm{HZ}$

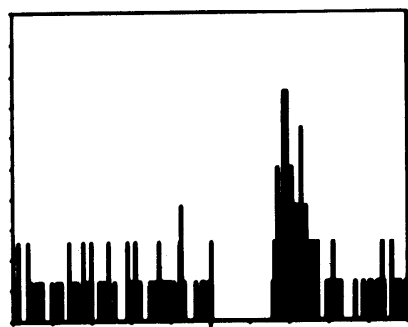

$-.26$

0

0.26

FIG. 11. Peristimulus time histograms of responses to SUM or MS stimulation. Examples include single spiking units from the stratum granulosum (SG), complex-spike cells from the hilus and CA1, and theta cells from CA1. Stimulation occurred at time 0 . Each example represents an average of 40 responses. Binwidth is $1 \mathrm{~ms}$. Many cells responded only by inhibition or excitation. Other responses were multiphasic. For example, MS stimulation of the unit shown in the upper right resulted in inhibition followed by postinhibitory excitation. Another cell recorded in SG responded to MS stimulation with 2 phases of excitation. Whereas the onset of a unit response was usually very distinct, occasionally we observed delayed effects with less distinct onset latencies. SUM activation of the CA1 complex-spike cell shown here provides an example of such a delayed response. 
mulation produced relatively large spike facilitation effects (see Fig. 7). For both MS and SUM, facilitation effects on the perforant path elicited population spike decreased with increasing size of the control response. No significant change in EPSP was observed (SUM: $1.2 \pm 1.6 \%$; MS: $-1.2 \pm 1.8 \%)$.

\section{Effects of SUM or MS stimulation on spontaneous hippocampal unit activity}

The different cell populations were first categorized during the recording session according to the depth of the recording electrode, spike width, and whether the cell fired single spikes or bursts of multiple spikes. A total of 125 hippocampal cells were recorded from 14 rats.

Units recorded from the SG of the dentate gyrus $(n=34)$ and CA1 theta cells $(n=16)$ fired single spikes of short duration (200-300 $\mu \mathrm{s}$; measured as the time difference between the points of maximum and minimum voltages on the analog waveform). Complex-spike cells recorded from CA1 $(n=44)$, hilus $(n=23)$ or CA $3(n=8)$ frequently fired in bursts of multiple spikes; the individual spike widths were 350-450 $\mu \mathrm{s}$ and successive spikes (which occurred $\sim 2.5-4.0 \mathrm{~ms}$ apart) within a burst exhibited a progressive decline in amplitude.
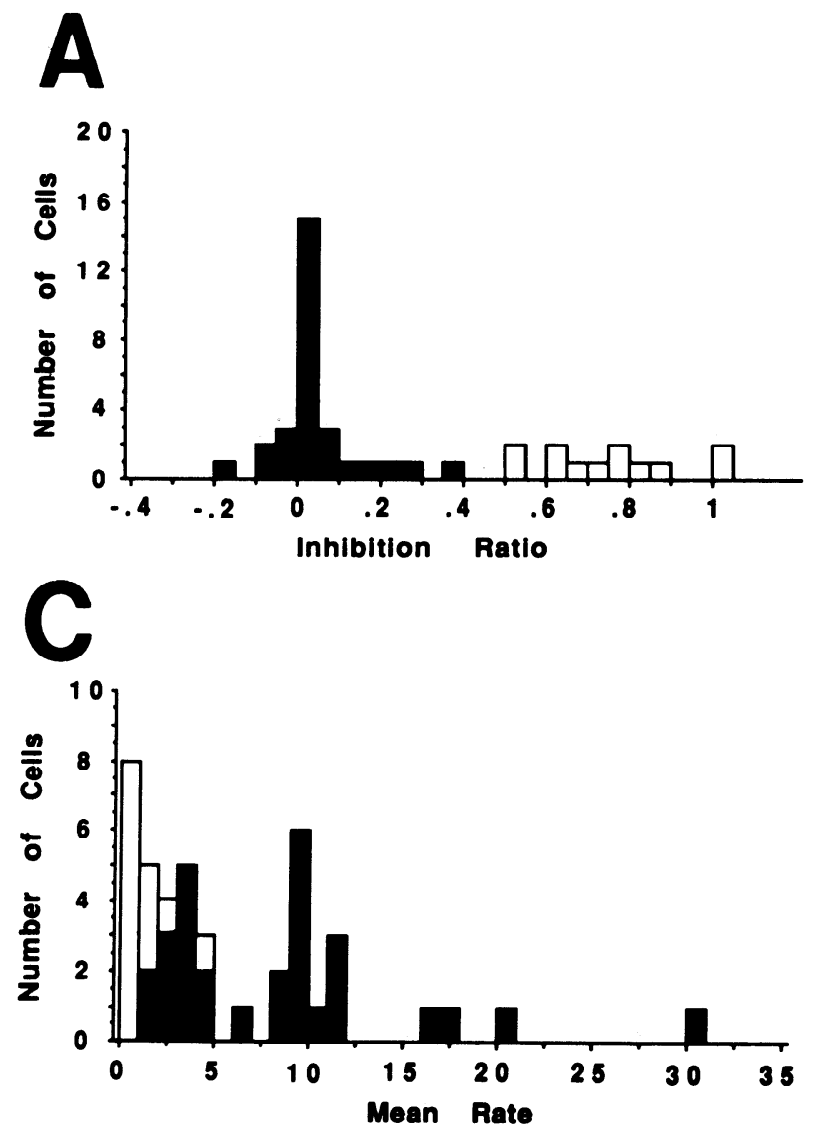

Interspike interval histograms presented in Fig. 8 illustrate the distributions of intervals on a log scale with a bin size of $0.02 \ln (\mathrm{ms})$. Eighty-five percent of the cells from SG were unimodally distributed. In contrast to units recorded in the SG, a unimodal distribution of interspike intervals was characteristic of only $23 \%$ of the theta cells. Histograms for complex-spike cells from all subfields were similar, and are consistent with observations that the complexspike cells most often fired in patterned, high-frequency bursts. The first peak on the left reflects the frequency distribution of interspike intervals within a burst, whereas the second peak reflects the distribution of intervals between successive bursts. Our finding that the interspike interval distribution is bimodal for all types of complexspike cells is consistent with the results from awake animals (16). Similarly, Ranck (23) has reported that the interspike intervals of CAl theta cells are less variable than those of CA1 complex-spike cells.

Autocorrelations were performed to assess the firing patterns of individual cell types (see Fig. 8 for representative examples). The autocorrelation function represents the expectation density for spikes preceding or following a spike at any particular time. A majority of SG units showed no apparent modulation apart from the relatively low expec-
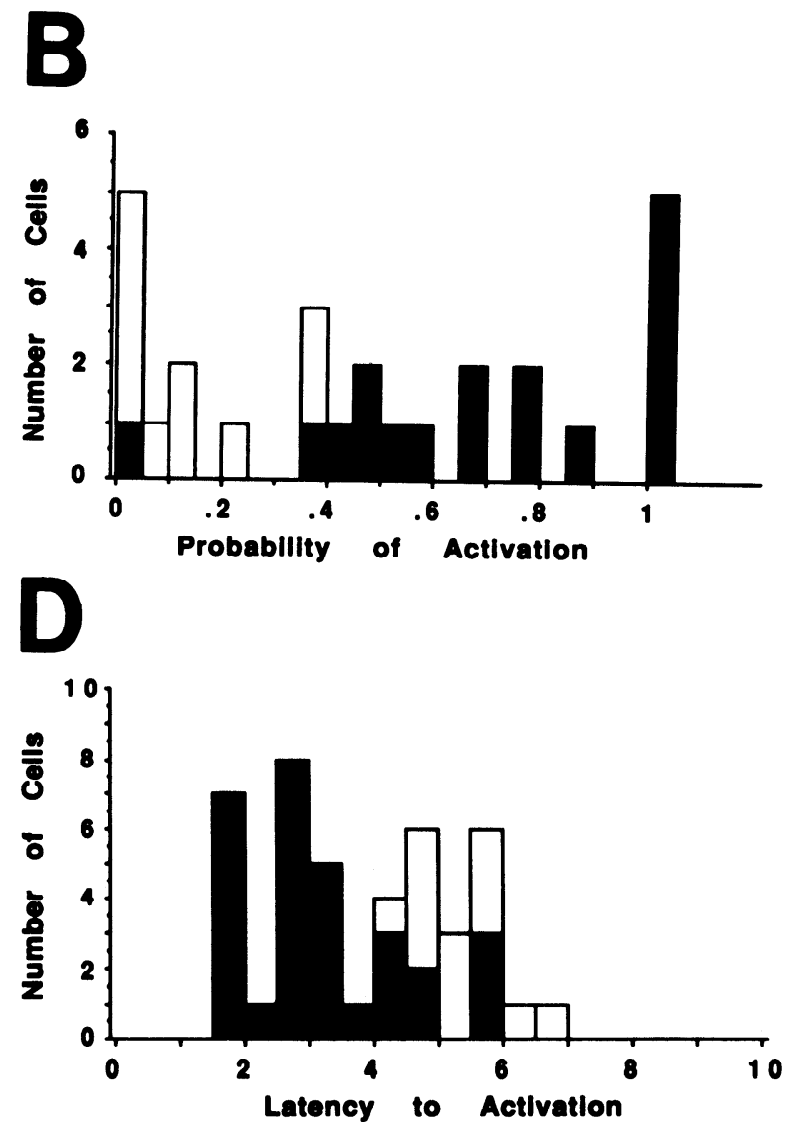

FIG. 12. Frequency distributions of different SG unit characteristics. $A$ : the distribution of paired-pulse inhibition ratios most clearly suggests that 2 cell types were recorded in SG. Cells inhibited during the period of population spike inhibition of the second field potential that resulted from 2 pulses delivered to the perforant path were classified as granule cells (open bars), whereas cells that fired with equal probability during the first and second field potentials were identified as basket cells (closed bars). $B$ : the distribution of the probability of unit activation with perforant path intensities below the threshold for a population spike suggest basket and granule cells can also be distinguished according to this measure. $C$ : the distribution of the mean spontaneous firing rate. $D$ : the latency to SG unit activation reveal separate, but overlapping, distributions of scores. 
tation at short intervals. Eighty-one percent of these cells exhibited a relatively flat autocorrelation function. The firing rate of $54 \%$ of the CA1 theta cells was modulated to varying degrees at a frequency of $\sim 3 \mathrm{~Hz}$. (Note: autocorrelation functions of SG and CA1 theta cells recorded from freely behaving rats may reveal a different ratio of rhythmic and nonrhythmic firing patterns; unpublished observations). Complex-spike cells recorded from the CA1, CA3, and hilus produced similar autocorrelation histograms: a sharp peak correlation was found around time zero, with no evidence of rhythmicity.

A one-factor analysis of variance (ANOVA) revealed that the average spontaneous firing rate varied according to the type of cell being recorded (see Fig. 9), $F(4,124)=$ $11.73, P<0.001$. Post hoc pairwise comparisons (Scheffé test, $\alpha=0.05$ ) indicated that the firing rate of CA1 theta cells was significantly higher than all other cell types and that SG units fired significantly faster than hilar or CA1 complex-spike cells. (As will be elaborated below, the population of SG units sampled probably comprised at least two cell types.)

Figure 10 summarizes the proportion of different classes of cells responding in either an excitatory or an inhibitory manner within $200 \mathrm{~ms}$ following stimulation of the SUM or MS. By "inhibition", we refer to a general decrease in firing rate that could be due either to decreased excitation or to synaptic inhibition. Peristimulus time histograms of inhibitory and excitatory responses to SUM or MS stimulation are shown in Fig. 11.

As can be seen from the examples provided, a given cell's
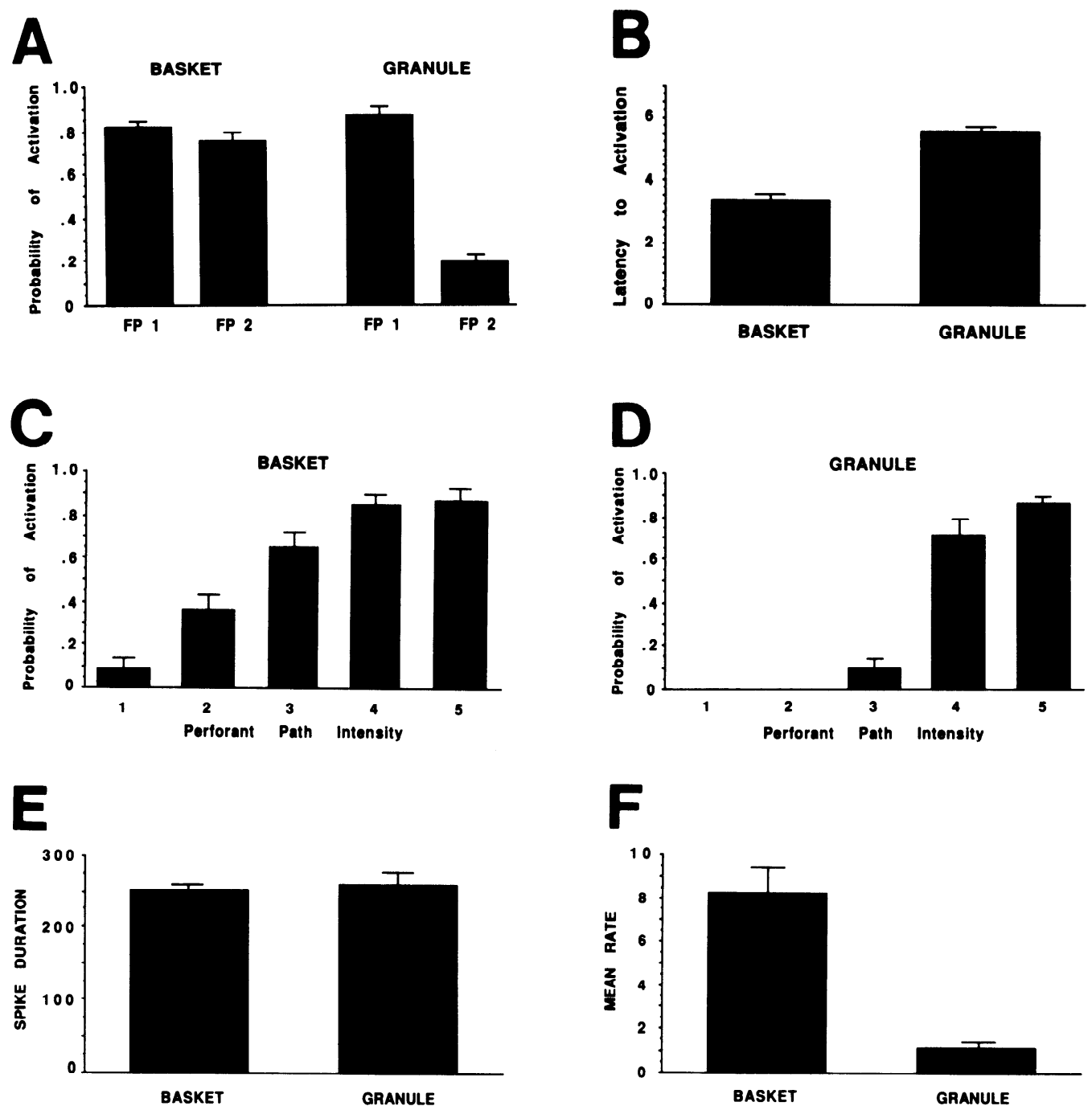

FIG. 13. $A$ : the probability of unit activation during the first and second field potentials (FP 1 and FP 2, respectively) elicited by 2 pulses delivered to the perforant path (interstimulus interval: $25 \mathrm{~ms}$ ). Units classified as basket cells discharged with equal probability during both field responses. In contrast, the probability of activation of granule cells was dramatically reduced during the second field response. $B$ : the latency to unit activation following a perforant path pulse that elicited a population spike that was $\sim 25 \%$ of maximum. Granule cells discharged at a longer latency than basket cells. $C$ and $D$ : the probability of basket and granule cell activation as a function of perforant path stimulus intensity. When the perforant path intensity was set below the threshold for detection of an EPSP (intensity level 1), just above the threshold for an EPSP (level 2), or just below the threshold for a population spike (level 3), basket and granule cells exhibited different probabilities of responding. Both cell types exhibited a high probability of discharge when the perforant path intensity was at (level 4) or above threshold (level 5) for a population spike. $E$ : a comparison of the spike widths ( $\mu$ s) of basket and granule cells revealed no difference. $F$ : the mean spontaneous firing rate $(\mathrm{Hz})$ of basket cells was significantly higher than that of granule cells. 
response often involved inhibition, followed by excitation, or vice versa. For the data presented in Fig. 10, cells were categorized according to the first response made following a stimulation event. In general, classification of a given response was straightforward. For example, almost all of the inhibited SG units showed complete (i.e., 100\%) inhibition. Three-fourths of excited SG cells demonstrated an increase of $200 \%$ or more. Unit responses were equally clear following either stimulation event.

Three patterns of response emerged as a result of MS or SUM stimulation: 1) Complex-spike cells, regardless of where they were recorded, typically were unaffected. Of those few that were affected, equal proportions responded with excitation or inhibition. 2) CA1 theta cells responded
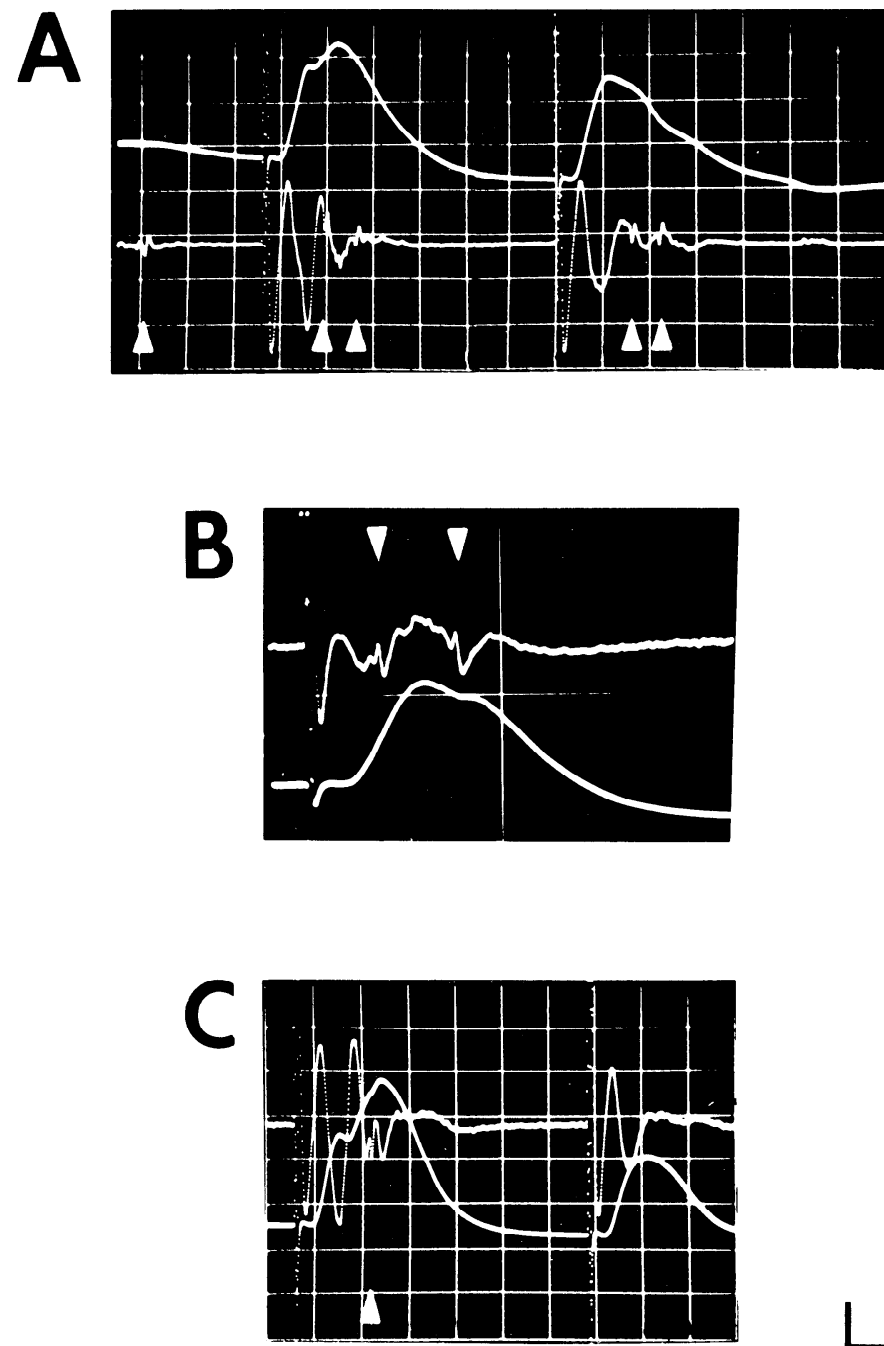

FIG. 14. Analog examples of unit activation during the perforant path-evoked field potential. The 2 traces in each part reflect the same signal with different filter settings adjusted to reveal either the field potential or the single-unit activity. $A$ : putative basket cell activation can be observed during the first and second field potentials that result from paired pulses delivered to the perforant path, even though the population spike was inhibited during the second response. $B$ : a different basket cell is shown to be activated before onset of the population spike. $C$ : this granule cell was activated during the first, but not the second, field response following paired-pulse stimulation of the perforant path. Arrows indicate unit discharge. (Calibration: $4 \mathrm{~ms} ; 250 \mu \mathrm{V}$ for unit traces and $5 \mathrm{mV}$ for field potential traces. Negative is up for unit traces presented in panels $A$ and $C$; negative is down for all field potentials and the unit trace in panel $B$ )

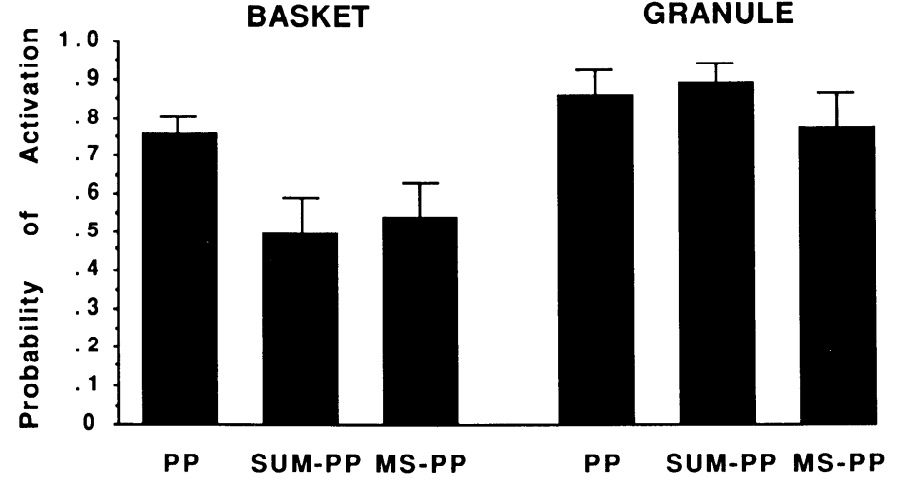

FIG. 15. A comparison of the effects of SUM or MS prestimulation on the probability of unit activation following a perforant path stimulation above population spike threshold. Basket cells were less likely to fire than granule cells when the perforant path stimulus was preceded by either SUM or MS stimulation.

more frequently to MS or SUM stimulation than did complex-spike cells. Excitatory and inhibitory responses occurred in roughly equal proportions following SUM stimulation. MS stimulation produced a somewhat higher proportion of inhibition. 3) Cells recorded within SG responded to either type of stimulation as frequently as CA1 theta cells. Almost all responses were inhibitory. The prestimulus mean rate of spontaneous discharge was significantly higher for cells inhibited by SUM or MS stimulation than for those that were excited or did not change following stimulation [mean \pm SE: $6.07 \pm 1.34$ and $2.68 \pm$ $0.71 \mathrm{~Hz}$, respectively; $F(1,28)=4.96, P<0.05]$. The mean latency to inhibition was significantly shorter than the latency to excitation $[7.0 \pm 2.3$ and $161.5 \pm 68.8 \mathrm{~ms}$, respectively, $F(1,34)=18.74, P<0.001]$.

Although most cells recorded from SG responded by decreasing their rates following MS or SUM stimulation, this was not reflected in the overall mean firing pattern (Fig. 5 , bottom). This was characterized by an increase, at short latencies, followed by a decrease and a subsequent secondary peak. The latter peak was due largely to postinhibitory excitation that was exhibited by many cells. Thus the average population activity of cells in SG is increased after MS or SUM stimulation, and this increase is due to a strong excitation of a small proportion of cells recorded.

\section{Effects of SUM or MS prestimulation on perforant path-induced unit discharge}

The primary goal of this experiment was to determine whether short duration (i.e., 200-300 $\mu$ s), single spiking units recorded in SG comprise one or more classes of cell type and whether these classes of cells are differentially affected by MS or SUM stimulation.

Measurements were obtained for the following parameters: spike duration, mean rate of spontaneous firing, latency to activation, the relative probability of unit discharge following the first and second stimuli of a paired stimulation of the perforant path, and the probability of unit activation as a function of perforant path intensity. Frequency distributions of four of these measures are presented in Fig. 12. Paired-pulse inhibition ratios were calculated by subtracting the probability of unit activation dur- 
ing the second field potential from the probability of discharge during the first field potential, then dividing by the sum of the two probabilities. These ratios were bimodally distributed. Units with ratios $>0.5$ were tentatively classified as granule cells $(n=12)$, whereas units with ratios < 0.5 were classified as basket cells $(n=29)$.

Figure 13 provides a comparison of cells classified as putative basket or granule cells on a number of physiological measures. When paired pulses were delivered to the perforant path (interstimulus interval, $25 \mathrm{~ms}$ ), a population spike was present during the first, not second, field response. Putative basket cells discharged with equal probability during the first and second field potentials, $F(1,28)=$ 3.58 , NS. In contrast, presumed granule cells were $67 \%$ less likely to fire during the second field response, $F(1,11)=$ 140.53, $P<0.001$. Analog examples of unit activation during the paired-pulse test are shown in Fig. 14.

Latency to activation of putative granule cells was significantly longer than that of putative basket cells (mean \pm SE: $5.7 \pm 0.2$ and $3.4 \pm 0.3 \mathrm{~ms}$, respectively; $F(1,25)=$ 28.95, $P<0.001$; see Fig. $13 B$ ). Granule cells always fired during the time window of the population spike whereas basket cells usually, but not always, fired before the population spike. For a subset of the cells in which stimulus intensity effects were examined, the probability of presumed granule $(n=9)$ or basket cell $(n=18)$ activation varied as a function of perforant path intensity, $F(4,8)=73.53, P<$ 0.001 and $F(4,17)=46.70, P<0.001$, respectively. However, the overall pattern of change in probability was different between cell types [see Fig. 13, $C$ and $D$; two-factor repeated measures ANOVA: $F(1,4)=5.77, P<0.001$ ]. Pairwise comparisons (Scheffé test, $\alpha=0.05$ ) revealed that granule cells were significantly less likely to fire than basket cells when the perforant path stimulus intensity was below the population spike threshold. Mean rates of spontaneous activity also differentiated putative granule and basket cell groups, $F(1,25)=14.29, P<0.001$. Granule cells fired at a mean rate of $1.13 \pm 0.43 \mathrm{~Hz}$, whereas basket cells fired at $8.26 \pm 1.19 \mathrm{~Hz}$ (see Fig. 13F). These two groups of cells did not differ significantly in spike duration [mean $\pm \mathrm{SE}$ : $251.8 \pm 6.1$ and $260.6 \pm 14.8 \mu \mathrm{s}, F(1,42)=0.42, \mathrm{NS}$; see Fig. $13 E$ ]. Only three basket, and no granule, cells exhibited rhythmic firing patterns similar to those of the CA1 theta cells (see Fig. 10 for an example).

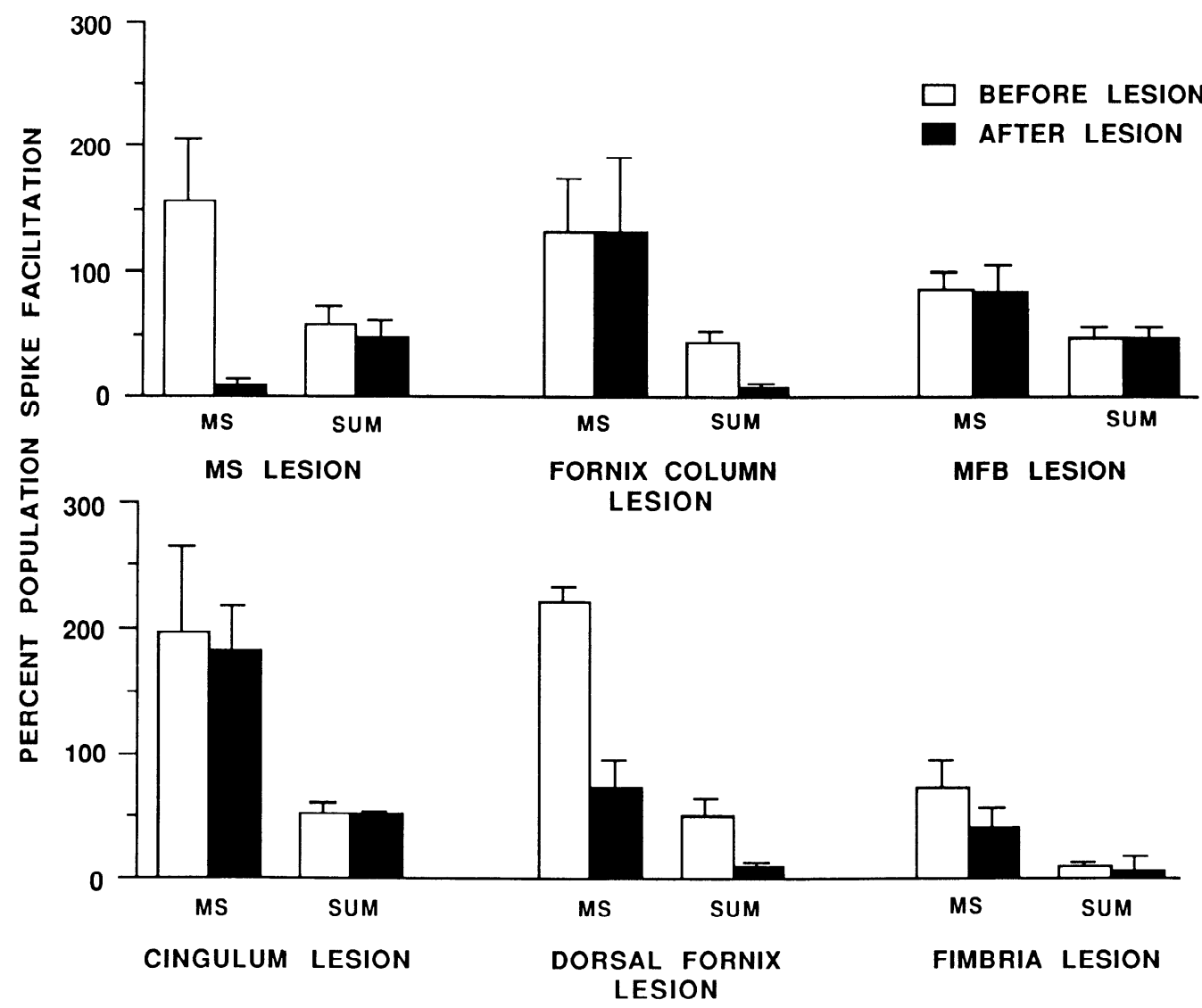

FIG. 16. The percent change in MS- and SUM-induccd spike facilitation before and after lesion of the MS, ipsilateral column of fornix, medial forebrain bundle (MFB), cingulum, dorsal fornix, or fimbria. Different rats sustained lesions of the MS, column of fornix or MFB. Five additional rats each sustained lesions of the cingulum, dorsal fornix, and fimbria. MS lesions eliminated MS spike facilitation while having no effect on SUM spike facilitation. Conversely, transection of the ipsilateral column of fornix eliminated SUM spike facilitation with no effect on MS spike facilitation. Neither MFB nor cingulum lesions affected MS or SUM spike facilitation. When the knife was advanced through the dorsal fornix, both SUM and MS spike facilitation was significantly reduced. However, prestimulation of the MS still produced a $73 \%$ increase in the PP-FD population spike. The attenuated MS-induced spike facilitation was again reduced by knife advancement through the fimbria. The pattern of effects shown here indicate that SUM and MS spike facilitation effects can occur independently of one another. SUM influences appear to arise through the fornix, whereas MS effects are mediated through the dorsal fornix and fimbria. 
The probability of putative granule cell $(n=11)$ discharge following perforant path activation was affected neither by MS or SUM prestimulation (see Fig. 15). In contrast, there was a statistically significant reduction in the likelihood of putative basket cell $(n=17)$ activation under the same conditions $[F(2,16)=8.19, P<0.01]$. On average, the reduction was $\sim 25 \%$. Over $70 \%$ of cells showed some reduction. Of these, the effects ranged from $20 \%$ to complete abolition of responses. Some basket cells were affected by one but not the other of MS or SUM prestimulation. Consistent with reports of others (e.g., Refs. 26 and 27), complex-spike cells found near the granule cell layer were not activated by perforant path stimulation.

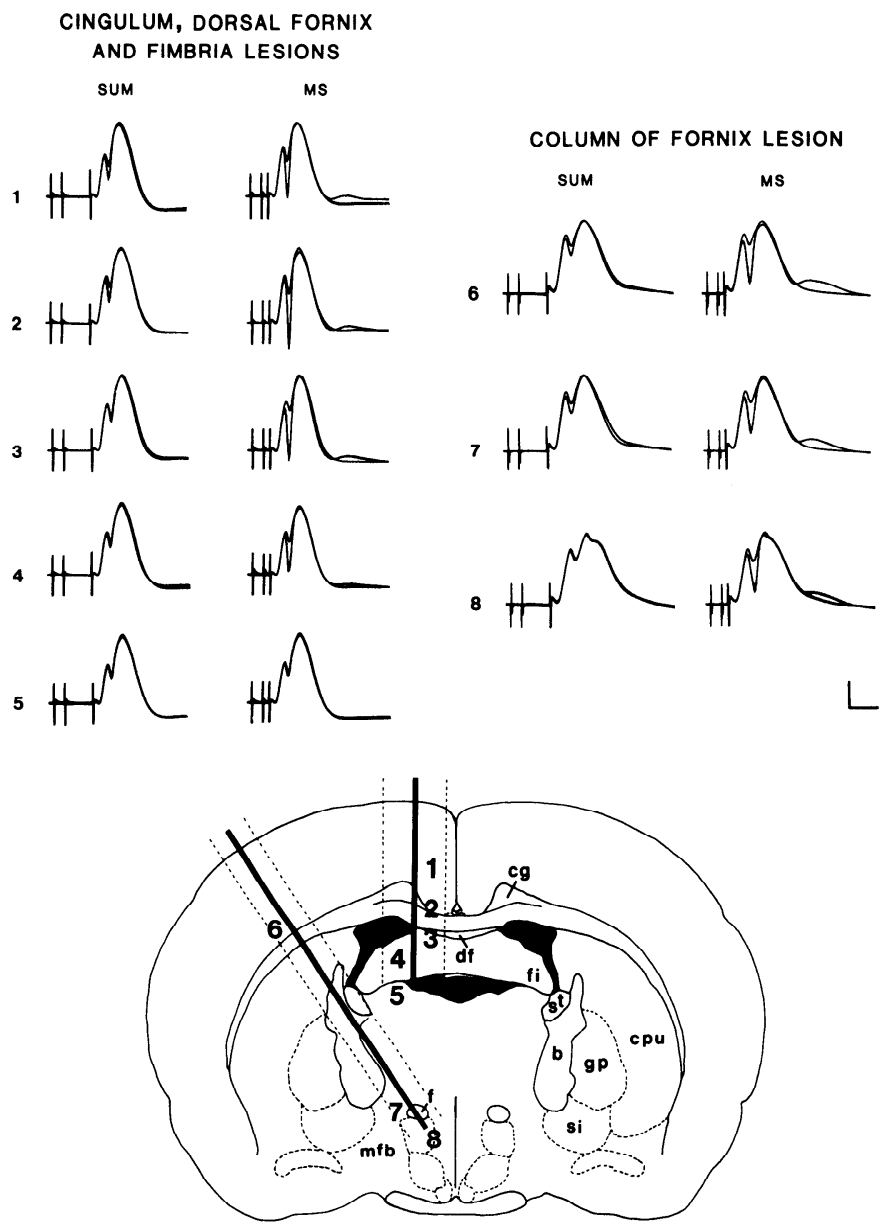

FIG. 17. Left: examples of SUM and MS spike facilitation as a knife was first advanced through the cingulum, then the ipsilateral dorsal fornix and fimbria. The area between the dashed lines illustrates the width of the knife cut. The numbers along the knife tract indicate different levels of knife advancement. Each illustration of a field response consists of 2 traces. Each pair of superimposed traces reflects the mean $( \pm \mathrm{SE})$ field response to 10 perforant path pulses given $10 \mathrm{~s}$ apart and 10 paired SUMPP or MS-PP stimulations. Neither SUM nor MS spike facilitation was affected by cingulum transection. On cutting the dorsal fornix, SUM spike facilitation disappeared and MS spike facilitation was significantly reduced. The MS facilitation effect was abolished following subsequent penetration through the fimbria. Right: an example of SUM- and MS-induced spike facilitation at different stages of knife advancement toward the ipsilateral column of fornix. SUM and MS spike facilitation were unchanged until the knife transected the column of fornix. Cutting the fornix eliminated SUM spike facilitation, but not MS spike facilitation (calibration: $5 \mathrm{~ms}, 10 \mathrm{mV}$ ). (Adapted from Ref. 21)
Effects of MS, fornix, medial forebrain bundle, cingulum, or fimbria lesion on SUM- and

MS-induced spike facilitation

A summary of the results of the lesion experiments is presented in Fig. 16. Before an MS lesion, MS and SUM prestimulation resulted in an average of $157 \%$ and $58 \%$ increase in the population spike, respectively $(n=5)$. Following the lesion, MS prestimulation had virtually no effect on the PP-FD population spike whereas SUM prestimulation resulted in a $48 \%$ increase in the population spike. The pre- and postlesion effects were statistically different following MS stimulation $(F(1,8)=9.29, P<$ $0.02)$, but were not different following SUM stimulation $(F(1,8)=0.25, \mathrm{NS})$.

Whereas transection of the ipsilateral column of fornix $(n=4)$ substantially reduced SUM-induced spike facilitation $(F(1,4)=12.15, P<0.02)$, medial forebrain bundle $(n=6)$ transection had no effect $(F(1,10)=0.001$, NS). Neither fornix or medial forebrain bundle lesion altered MS-induced spike facilitation $(F(1,4)=0.001$, NS and $F(1,10)=0.001$, NS, respectively). Apparently, the ipsilateral fornix contains fibers that mediate the SUM effect on the PP-FD population spike.

Ipsilateral cingulum transection did not alter MS- or SUM-induced spike facilitation $(F(1,8)=0.04$, NS and $F(1,8)=0.01$, NS, respectively, $n=5)$. In contrast, cutting the ipsilateral dorsal fornix significantly reduced both MS and SUM spike facilitation $(F(1,8)=38.86, P<0.001$ and $F(1,8)=10.09, P<0.02$ ). Although MS spike facilitation was attenuated following dorsal fornix transection, a $73 \%$ increase in the PP-FD population spike was still observed following prestimulation of the MS. MS spike facilitation was further reduced to $42 \%$ as the knife continued to be advanced through the fimbria $(F(1,8)=1.45, \mathrm{NS})$. That complete elimination of MS spike facilitation was not reflected in the group means presented in Fig. 16 may be due to the fact that the knife did not always completely transect the fimbria. Figure 17 illustrates the change in spike facilitation following MS or SUM prestimulation as a knife was advanced through the cingulum and dorsal fornix to the fimbria, or toward the ipsilateral column of fornix.

\section{DISCUSSION}

The present study addressed the following questions. 1) How do supramammillary (SUM) afferents affect hippocampal physiology? 2) How do these supramammillary influences compare with those of afferents from the medial septum (MS)? 3) To what extent might supramammillary effects be mediated by the medial septum?

Stimulation of the SUM nucleus significantly facilitated the population spike, but not the EPSP, of the PP-FD field potential. A similar finding was described by Winson (39). In addition, a reduction of EPSP amplitude at spike onset was observed, indicating less synaptic current was required to discharge granule cells. MS prestimulation produced a similar pattern of effects on the dentate field response, but the magnitude was $\sim 3$ times greater than that observed following SUM prestimulation. This difference does not necessarily reflect qualitatively unique or independent influences. Rather, SUM-induced spike facilitation may have 
been smaller than that induced by MS prestimulation because of differences in the number of afferent cells affected by the stimulus, and/or differences in the number of terminals affected per afferent cell activated.

The most frequently observed response of units recorded in the stratum granulosum (SG) to SUM or MS stimulation was a reduction in spontaneous activity. A small number of units, however, exhibited a marked increase in firing rate, a finding also reported by McNaughton and Miller (18). In general, it was the high-rate cells that were suppressed and the low-rate cells that showed either no effect or an increase. Although we cannot be certain as to the identity of the cells recorded in experiment 2 , the results of experiment 3 (discussed below) lead to the conclusion that the inhibited cells were basket interneurons, whereas the excited units were granule cells.

In experiment 3 it was shown that short-duration, single spiking cells recorded in SG could be classified into two categories, which were tentatively identified as basket or granule cells according to several physiological criteria: the paired-pulse inhibition ratio, the probability of activation with a stimulus intensity set just below the threshold for a population spike, the mean spontaneous firing rate, and the latency to activation at a stimulus intensity sufficient to elicit a population spike of $\sim 25 \%$ maximum. Of these criteria, the first two were most discriminative, resulting in clcarly bimodal distributions. Putative basket cells had significantly higher spontaneous discharge rates, fired at a low-stimulus threshold with short latency (usually before any population spike), and were not suppressed during paired stimulation of the perforant path at intervals generating population spike inhibition. The response of these cells to perforant path stimulation was significantly inhibited following SUM or MS prestimulation. On the other hand, putative granule cells had low spontaneous rates, fired at a higher-stimulus threshold with longer latency (within the population spike window), and were significantly suppressed during the paired-pulse interval in which the population spike was reduced.

The activation of putative granule cells by perforant path stimulation was not significantly facilitated by either SUM or MS prestimulation in experiment 3. Whereas this may appear inconsistent with the inhibited response of the basket cells and with the facilitated population spike, it should be pointed out that, unlike experiment 2, putative granule cells of experiment 3 were initially identified in the physiological record on the basis of their activation by perforant path stimulation, and not on the basis of spontaneous activity. Cells with low spontaneous rates that were not activated by perforant path stimulation would have been overlooked. Because the granule cells fire a single spike in response to perforant path activation, a ceiling effect undoubtedly accounts for the lack of observable MS or SUM influence in this experiment. The overall pattern of results suggests that, at least under the present experimental conditions, granule cells remain relatively silent until afferent pathways are activated.

Segal (30) concluded that granule cells are inhibited by SUM stimulation. However, in that study, no physiological criteria were used to distinguish between SG cell types. In contrast, our analyses suggest that the probability of dis- charge of individual granule cells is either increased or unaffected by either SUM or MS stimulation, whereas the activity of basket cells is significantly suppressed. This apparent discrepancy may be related to the fact that basket cells are more easily detected than granule cells because of their higher spontaneous rates. Basket cells may thus have comprised the bulk of Segal's sample.

The results of the electrolytic and knife-cut lesion study strongly support the hypothesis that SUM and MS influences are independent. Given that SUM efferents had been described in the MS (e.g., Ref. 34), it was possible that the SUM spike facilitation effect was mediated via septal cells. However, because lesions of the MS or medial forebrain bundle (which carry SUM fibers to the MS) did not affect SUM spike facilitation, it is possible to conclude that the effect is not mediated by the septum. That the SUM effect was eliminated following fornix transection supports the contention that SUM afferents to the granular layer are located in the ipsilateral column of fornix and dorsal fornix, as suggested by the anatomic study of Veazey et al. (34). Because elimination of the SUM facilitation effect did not affect MS-induced spike facilitation, the septal influence must arise independently from the SUM. In particular our data indicate that, at least with respect to the dorsal hippocampus, relevant MS afferents course through the dorsal fornix and fimbria and not through the cingulum bundle.

Several different hypotheses have been put forth to account for spike facilitation effects observed following subcortical prestimulation. For example, Assaf and Miller (4) found that prestimulation of the median raphe nucleus facilitates the PP-FD population spike with no change in the EPSP. The time course of inhibition of presumed granule cells caused by raphé stimulation corresponded to the optimal interstimulus interval for the spike facilitation effect. Therefore, it was proposed that widespread inhibition of granule cells resets their random activity such that more cells fire in synchrony on subsequent activation of perforant path fibers. This reset hypothesis implies that reduced refractoriness in the granule cell population is responsible for the spike facilitation effect. This seems a priori unlikely as an explanation of the present results because the mean firing rate of putative granule cells under Nembutal anesthesia was $<2 \mathrm{~Hz}$. Even for the higher-rate putative basket cells, the proportion of cells that would be refractory at any given time would be far too low to account for the observed changes in the population spike. As in the case of the study by Segal (30), the electrophysiological criteria used by Assaf and Miller to identify units as granule cells were limited, and we consider it likely that most of the sample consisted of basket cells.

A second hypothesis to account for the SUM and MS spike facilitation effect is that prestimulation of these afferents directly depolarizes granule cells. However, such a direct depolarizing influence sufficient to elicit substantially greater cell discharge would be expected to have been accompanied both by a significant field potential independent of the perforant path and by a reduction in the field perforant path-elicited EPSP due to the reduced driving force for synaptic current flow (cf Ref. 15). Such a reduction was not observed in this study, nor was it reported in 
the earlier studies of Assaf and Miller (4) or Bilkey and Goddard $(5,6)$. Thus direct depolarization is unlikely to account for the increased population spike. It remains possible, however, that there may be a direct influence on granule cell membrane resistance, for example, one acting in a manner similar to the muscarinic inactivation of potassium conductance.

A third hypothesis that has been proposed $(5,6,10)$ is that MS-induced spike facilitation involves inhibition of inhibitory interneurons found in the dentate region. Application of $\gamma$-aminobutyric acid (GABA) antagonists to the hilar region blocked the MS spike facilitation effect (5). Also, MS stimulation attenuated PP-FD population spike inhibition produced either by paired pulses applied to the perforant path, or by commissural prestimulation $(5,6)$. Robinson and Racine $(24,25)$, however, have reported that MS stimulation had no influence on the effects of paired pulses applied to the perforant path. Because the interval between perforant path pulses was relatively short in the study by Bilkey and Goddard (i.e., 10-20 ms) and longer in Robinson and Racine's experiments (i.e., $>20 \mathrm{~ms}$ ), it is difficult to compare results of the two studies directly. Consistent with the disinhibition hypothesis are the findings that GABAergic MS cells do project to the hippocampus (14), and a reduction of septal GABAergic cells is observed following fimbria-fornix lesions (22).

The pattern of results described in the present study support the disinhibition explanation of spike facilitation by providing direct evidence that basket cells are less likely to fire when MS stimulation precedes a perforant path pulse. Consistent with this result was our finding that when MS prestimulation occurred, less synaptic current was required to elicit a population spike. SUM-induced spike facilitation may similarly be explained with the disinhibition hypothesis. However, in the present experiments, there is a discrepancy between the relative magnitudes of the effects of stimulation of the two pathways on the perforant path-elicitcd population spike (experiment 2) and the attenuation of basket cell discharge probability (experiment 3 ). Whereas MS prestimulation produced considerably more population spike facilitation than SUM prestimulation, there was no between-pathway difference in the suppression of basket cell activation via the perforant path. This may indicate either that the disinhibition hypothesis provides only a partial explanation for the MS effect (as alluded to above), or that the two pathways terminate differentially on different populations of basket cells that have different relative efficacies in the inhibition of the granule cells. Such a differential distribution would be consistent with the differential terminal fields of the two pathways.

Two major fiber bundles lie close to the SUM stimulation site: the mammillothalamic tract and the fornix. Therefore, the possibility exists that the spike facilitation effect observed in this study resulted from activation of these fibers rather than SUM cells. We believe that unintentional activation of the mammillothalamic tract is an unlikely explanation of our data because the SUM spike facilitation effect disappeared in preparations that had fornix transections and intact mammillothalamic tracts. This finding, however, does not permit one to determine whether stimulation of the fornix per se was critical for observation of the spike facilitation effect. Additionally, it should be noted that, at present, polysynaptic effects cannot be completely ruled out, although the very short latency to the onset of inhibition of putative basket cells makes such an explanation unlikcly.

Dahl and Winson (9) reported that prestimulation of the parafascicular region caudal to the SUM also results in facilitation of the PP-FD population spike with no change in the population EPSP. It is not clear whether the parafascicular prestimulation effect is related to the SUM spike facilitation described in the present study. Although the stereotaxic coordinates used for placement of the parafascicular and SUM stimulating electrodes were $\sim 1 \mathrm{~mm}$ apart, current spread may have resulted in stimulation of a common critical nucleus. However, both Dahl and Winson's threshold/depth curves, and the specificity of effects obtained in the present study in relation to the medial-lateral localization of the electrode, suggest that in neither study can current spread explain the similar results. In addition, the time course of the effects in the two studies are somewhat different, suggesting that functionally different cells might be involved at the two locations.

Vertes (36) postulated that the SUM nucleus serves as a relay station for pontine reticular formation influences on hippocampal theta activity. The main evidence in support of this hypothesis comes from a report that increased theta activity results from electrical stimulation in the vicinity of the SUM (35). Anatomic data support Vertes' finding: the pontine nuclei project to the SUM (37), and the SUM projects to an area of the brain known to be important for the generation of hippocampal theta, the MS $(7,35)$. Additional investigations of the possible contribution of the SUM nucleus to hippocampal theta activity would facilitate an understanding of SUM-hippocampal interactions.

The results of this study demonstrate that the SUM nucleus can significantly influence hippocampal physiology in the Nembutal-anesthetized rat. In particular, the pattern of results described above suggest that SUM- (or MS-) induced facilitation of the PP-FD population spike can be partially accounted for by the prestimulation-induced disinhibition of granule cells. Preliminary evidence from ongoing experiments indicates that, like the MS spike facilitation effect, SUM-induced facilitation of the PP-FD population spike can be readily demonstrated in chronically prepared, freely behaving rats. Investigations of the SUM effects on physiological phenomena such as feed-forward, recurrent, or commissural inhibition of dentate cellular activity will help to resolve the issue of qualitative differences or similarities between the SUM- and MS-spike facilitation effects. Similarly, elucidation of the specific neurochemical nature of SUM terminals will permit more detailed qualitative comparisons between SUM and MS inputs to the dentate gyrus. Because the SUM nucleus can influence a structure thought to be critical for normal memory function (i.e., the hippocampus, Ref. 29), it will be of interest also to determine the specific contribution, if any, that the SUM makes to learning and memory processes.

We thank J. Keith for his assistance during the initial stages of this study and R. Racine for his helpful suggestions on an earlier version of this manuscript. Also, we express appreciation to C. Elkins, K. Grewell, G. Rao, and S. Scott for their assistance with histology, figure preparations, 
and system programming, and J. G. Canfield and B. Jones-Leonard for the fluoro-gold preparations.

This research was supported by a postdoctoral National Research Service Award to S. J. Y. Mizumori from the National Institute on Aging Grant AG-05375; National Institute of Neurological and Communicative Disorders and Stroke Grant NS-20331 to B. L. McNaughton; and Grant AG-03376 to C. A. Barnes.

Received 21 September 1987; accepted in final form 9 August 1988.

\section{REFERENCES}

1. Alvarez-Leefmans, F. J. and Gardner-Medwin, A. R. Influences of the septum on the hippocampal dentate area which are unaccompanied by field potentials. J. Physiol. Lond. 249: 14P-16P, 1975.

2. Amaral, D. G. AND Cowan, W. M. Subcortical afferents to the hippocampal formation in the monkey. J. Comp. Neurol. 189: 573-591, 1980.

3. ANDERSEN, P., Bliss, T. V. P., ANd Skrede, K. K. Unit analysis of hippocampal population spikes. Exp. Brain Res. 13: 208-221, 1971.

4. ASSAF, S. Y. AND MilleR, J. J. Neuronal transmission in the dentate gyrus: role of inhibitory mechanisms. Brain Res. 151: 587-592, 1978.

5. BILKEY, D. K. AND GODDARD, G. V. Medial septal facilitation of hippocampal granule cell activity is mediated by inhibition of inhibitory interneurons. Brain Res. 361: 99-106, 1985.

6. BILKEY, D. K. AND GODDARD, G. V. Septohippocampal and commissural pathways antagonistically control inhibitory interneurons in the dentate gyrus. Brain Res. 405: 320-325, 1987.

7. BLAND, B. H. The physiology and pharmacology of hippocampal formation theta rhythms. Prog. Neurobiol. Lond. 26: 1-54, 1986.

8. DAHL, D. AND WINSON, J. Action of norepinephrine in the dentate gyrus. I. Stimulation of locus coeruleus. Exp. Brain Res. 59: 491-496, 1985.

9. DAHL, D. AND WINSON, J. Influence of neurons of the parafascicular region on neuronal transmission from perforant pathway through dentate gyrus. Brain Res. 377: 391-396, 1986.

10. FANTIE, B. D. AND GodDaRD, G. V. Septal modulation of the population spike in the fascia dentata produced by perforant path stimulation in the rat. Brain Res. 252: 227-237, 1982.

11. FoX, S. E. AND RANCK, JR., J. B. Localization and anatomical identification of theta and complex spike cells in dorsal hippocampal formation of rats. Exp. Neurol. 49: 299-313, 1975.

12. Haglund, L., Swanson, L. W., AND Köhler, C. The projection of the supramammillary nucleus to the hippocampal formation: an immunohistochemical and anterograde transport study with the lectin PHA-L in the rat. J. Comp. Neurol. 229: 171-185, 1984.

13. Harley, C. W., LaCaille, J.-C., and Galway, M. Hypothalamic afferents to the dorsal dentate gyrus contain acetylcholinesterase. Brain Res. 270: 335-339, 1983.

14. Köhler, C., Chan-Palay, V., and Wu, J.-Y. Septal neurons containing glutamic acid decarboxylase immunoreactivity project to the hippocampal region in the rat brain. Anat. Embryol. 169: 41-44, 1984.

15. McNaughton, B. L. And Barnes, C. A. Physiological identification and analysis of dentate granule cell responses to stimulation of the medial and latcral perforant pathways in the rat. J. Comp. Neurol. 175: 439-454, 1977.

16. McNaughton, B. L., Barnes, C. A., And O'Keefe, J. The contribution of position, direction, and velocity to single unit activity in the hippocampus of freely-moving rats. Exp. Brain Res. 52: 41-49, 1983.

17. MCNaughton, B. L., O'Keefe, J., And Barnes, C. A. The stereotrode: a new technique for simultaneous isolation of several single units in the central nervous system from multiple unit records. $J$. Neurosci. Methods 8: 391-397, 1983.

18. McNaughton, N. AND Miller, J. J. Medial septal projections to the dentate gyrus of the rat: Electrophysiological analysis of distribution and plasticity. Exp. Brain Res. 56: 243-256, 1984.
19. Mizumori, S. J. Y., McNaughton, B. L., Barnes, C. A., And KEITH, J. Supramammillary influences on hippocampal physiology: facilitation of granule cell responsivity to perforant path stimulation. Soc. Neurosci. Abstr. 12: 1528, 1986.

20. MOSKO, S., LYNCH, G., AND COTMAN, C. W. The distribution of septal projections to the hippocampus of the rat. J. Comp. Neurol. 152: 163-174, 1973.

21. Paxinos, G. AND Watson, C. The Rat Brain in Stereotaxic Coordinates. Sidney, Australia: Academic, 1982.

22. Peterson, G. M., Williams, L. R., Varon, S., and Gage, F. H. Loss of GABAergic neurons in medial septum after fimbria-fornix transection. Neurosci. Lett. 76: 140-144, 1987.

23. RANCK, JR., J. B. Studies on single neurons in dorsal hippocampal formation and septum in unrestrained rats. Part I. Behavioral correlates and firing repertoires. Exp. Neurol. 41: 461-531, 1973.

24. ROBINSON, G. B. AND RACINE, R. J. Interactions between septodentate and perforant-path inputs to the dentate gyrus. Soc. Neurosci. Abstr. 10: 79, 1984.

25. RoBinson, G. B. AND RACINE, R. J. Interactions between septal and entorhinal inputs to the rat dentate gyrus: facilitation effects. Brain Res. 379: 63-67, 1986.

26. Rose, G. Physiological and behavioral characteristics of dentate granule cells. In: Neurobiology of the Hippocampus, edited by $\mathrm{W}$. Seifert. New York: Academic, 1983, p. 449-472.

27. Rose, G., DiAmond, D., AND LyNCH, G. S. Dentate granulc cells in the rat hippocampal formation have the behavioral characteristics of theta neurons. Brain Res. 266: 29-37, 1983.

28. SCHMUED, L. C. AND Fallon, J. H. Fluoro-gold: a new fluorescent retrograde axonal tracer with numerous unique properties. Brain Res. 377: 147-154, 1986.

29. SCOVILLE, W. B. AND MILNER, B. Loss of recent memory after bilateral hippocampal lesions. J. Neurol. Neurosurg. Psychiatry 20: 11-21, 1957.

30. SEGAL, M. A potent inhibitory monosynaptic hypothalamohippocampal connection. Brain Res. 162: 137-141, 1979.

31. Segal, M. AND LANDis, S. Afferents to the hippocampus of the rat studied with the method of retrograde transport of horseradish peroxidase. Brain Res. 78: 1-15, 1974.

32. Shin, C., Scialabba, F. A., AND McNamara, J. O. Stimulation of substantia nigra pars reticulata enhances dentate granule cell excitability. Brain Res. 411: 21-27, 1987.

33. Swanson, L. W. AND Cowan, W. M. The connections of the septal region in the rat. J. Comp. Neurol. 186: 621-656, 1979.

34. Veazey, R. B., Amaral, D. G., AND Cowan, W. M. The morphology and connections of the posterior hypothalamus in the cynomolgus monkey (Macaca fascicularis). II. Efferent connections. $J$. Comp. Neurol. 207: 135-156, 1982.

35. VERTES, R. P. An analysis of ascending brain stem systems involved in hippocampal synchronization and desynchronization. J. Neurophysiol. 46: 1140-1159, 1981.

36. VERTES, R. P. Brainstem modulation of the hippocampus. Anatomy, physiology, and significance. In: The Hippocampus, edited by R. L. Isaacson and K. Pribram. New York: Plenum, 1986, vol. 4, p. 41-75.

37. Vertes, R. P., Waltzer, R., and Martin, G. F. An autoradiographic study of ascending projections from the pontine and reticular formation in the rat. Soc. Neurosci. Abstr. 12: 1547, 1986.

38. WINSON, J. Reticular formation influence on neuronal transmission from perforant pathway through dentate gyrus. Brain Res. 225: 37-49, 1981.

39. WinSON, J. Neuronal transmission through the hippocampus: dependence on behavioral state. In: Cortical Integration, edited by F. Reinoso-Suarez and C. Ajmone-Marsan. New York: Raven, 1984, p. 131-146.

40. Wyss, J. M., Swanson, L. W., AND Cowan, W. M. Evidence for an input to the molecular layer and the stratum granulosum of the dentate gyrus from the supramammillary region of the hypothalamus. Anat. Embryol. 156: 165-176, 1979. 